\title{
Regioselective Electrophilic Aromatic Substitution Reactions over Reusable
}

\section{Zeolites}

Keith Smith* and Gamal A. El-Hiti†

Centre for Clean Chemistry, Department of Chemistry, University of Wales Swansea, Singleton Park, Swansea, SA2 8PP, UK

* Address correspondence to this author at Centre for Clean Chemistry, Department of Chemistry, University of Wales Swansea, Singleton Park, Swansea, SA2 8PP, UK; Tel.; +44-1792295266; fax: +44-1792295261; E-mail: k.smith@swansea.ac.uk 
Abstract: Zeolite catalysts can play an important role in the development of greener organic syntheses through their abilities to act as heterogeneous catalysts, support reagents, entrain by-products, avoid aqueous work-ups and enhance product selectivities via shape-selectivity. We have shown that zeolites under modest conditions can have advantages in para-regioselective nitration, alkylation, acylation, methanesulfonylation and halogenation of aromatic compounds. They can also assist in the electrophilic rearrangement of aryloxiranes. The zeolites can be easily removed from reaction mixtures by filtration and regenerated by heating and can then be reused several times to give the same selectivity.

Key words: Heterogeneous Catalysis, Zeolites, Electrophilic Substitution Reactions; para-Substituted Aromatics, Shape Selectivity, Regioselectivity.

\section{INTRODUCTION}

The synthesis of valuable industrial, pharmaceutical, agrochemical and fine chemicals frequently involves electrophilic aromatic substitution reactions. Indeed, substituted aromatic compounds represent useful intermediates in many synthetic processes. For example: i) aromatic nitro compounds are versatile chemical feedstocks for a wide range of industrial products, such as pharmaceuticals, agrochemicals, dyestuffs and explosives; ii) regioselective dialkylation of naphthalene is of great interest as 2,6-dialkylnaphthalenes can be oxidised to naphthalene-2,6-dicarboxylic acid, used to prepare the commercially valuable poly(ethylene naphthalenedicarboxylate) (PEN), which is increasingly finding use in films, liquid crystal polymers, packaging, coatings and adhesives; iii) acetylation of aromatic compounds is an important tool for the synthesis of aromatic ketones, some of which are useful intermediates for the synthesis of valuable industrial and pharmaceutical compounds; iv) some sulfones are useful intermediates in organic synthesis, with applications in agrochemicals, polymers and other industrial fields; v) halogenated aromatic compounds have numerous applications as fine chemicals and for the synthesis of bio-active compounds such as pesticides and pharmaceuticals and are also useful precursors of the corresponding organometallic compounds. However, the commercial syntheses of these compounds commonly suffer serious disadvantages, including some or all of the following: the requirement for large quantities of mineral or Lewis acids as activators, which on work-up may be hydrolysed with generation of large quantities of corrosive and toxic waste by- 
products; the use of stoichiometric quantities of toxic reagents, producing copper or other metal salts as waste; poor yields; or production of mixtures of regioisomers with low selectivity [1-11].

Major efforts are therefore being made to develop clean and environmentally friendly processes, particularly for the regioselective production of para-substituted products. The ability to control the selectivity of the substitution process is fundamental to achieving success in the area, but often there are few features to give assistance. Therefore, it is necessary to gain control through the use of external agents. It is well recognised that zeolite catalysts can play an important role in the development of greener organic synthesis through their abilities to act as recyclable heterogeneous catalysts, support reagents, entrain by-products, avoid aqueous work-ups and enhance product selectivities [12-24]. The presence of solid zeolites in liquid phase reactions can provide sites capable of enhancing the reaction rate in either a stoichiometric or catalytic manner. Moreover, by having these sites located within the rigid pores of the inorganic matrix they also impose additional constraints on the reacting partners, favouring the production of one regioisomer, usually the most linear one (e.g. the para-isomer), over other possible ones (e.g. ortho-).

We have been investigating the use of recoverable and regenerable zeolites in electrophilic substitution of aromatics. In our studies, we have shown that zeolites can be used successfully in the development of cleaner para-regioselective reactions including nitration, alkylation, acylation, halogenation and methanesulfonylation of aromatic compounds. Some of our progress in this area is reported in this review. We also report on the use of zeolites as catalysts for rearrangement of epoxides.

\section{REGIOSELECTIVE NITRATION OF AROMATIC COMPOUNDS}

Nitration of aromatic compounds is one of the most important and widely studied chemical reactions $[25,26]$. Traditionally, nitration has been performed with a mixture of nitric and sulfuric acids. However, this method is often highly unselective for nitration of substituted aromatic compounds and disposal of the spent acid reagents represents a serious environmental issue [27-30]. In order to address these problems several alternative methods for aromatic nitration have been developed. The use of solid catalysts is potentially attractive because of the ease of recovery and reuse of the catalyst, with the added possibility that the solid might enhance the selectivity, particularly if the solid 
has regular pores of molecular dimensions, which is the case with zeolites. Therefore, we undertook to study nitration of aromatic compounds over zeolite catalysts.

\subsection{Selective Nitration of Moderately Activated Substrates}

Regioselective nitration of toluene and other simple aromatics over zeolite catalysts has been the subject of much study [31-58], and it has become clear that the selectivity of the reaction depends on the nature of both the catalyst and the nitrating agent.

It is useful to consider the role a zeolite might play in the reaction. In a traditional 'mixed acid' nitration, the nitric acid, $\mathrm{HNO}_{3}$, is the source of the nitro group that becomes incorporated into the aromatic product, but without the sulfuric acid the reaction is slow and low-yielding. The sulfuric acid providess a level of acidity that encourages formation of the active nitrating species, nitronium ion (Equation 1), and a means of deactivating the water produced alongside the nitronium ion, again perhaps involving protonation (e.g. Equation $\mathbf{2}$ or Equation 3). If a zeolite were to replace sulfuric acid directly in the reaction, it would need to fulfil both of these roles.

$$
\begin{array}{llll}
\mathrm{H}^{+}+\mathrm{HNO}_{3} & \rightleftharpoons \mathrm{H}_{2} \mathrm{O}+\mathrm{NO}_{2}^{+} \\
\mathrm{H}_{2} \mathrm{SO}_{4}+\mathrm{H}_{2} \mathrm{O} & \rightleftharpoons \mathrm{H}_{3} \mathrm{O}^{+}+\mathrm{HSO}_{4}^{-} \\
\mathrm{HSO}_{4}^{-}+\mathrm{H}_{2} \mathrm{O} & \rightleftharpoons \mathrm{H}_{3} \mathrm{O}^{+}+\mathrm{SO}_{4}^{2-}
\end{array}
$$

Zeolites can indeed offer highly acidic sites, perhaps as acidic as those present in concentrated sulfuric acid, but such strongly acidic sites occur only in zeolites with relatively high Si:Al ratios. Such a zeolite can arbitrarily be represented by a formula for the proton form of an aluminosilicate with a 20:1 Si:Al ratio, $\mathrm{H}\left(\mathrm{SiO}_{2}\right)_{20}\left(\mathrm{AlO}_{2}\right)$, which has a relative mass of over 1000 Dalton per proton.

If it were assumed that a convenient reaction profile for a 'mixed acid' reaction would be achieved using two moles of sulfuric acid (one to effect Equation 1 and one to effect Equation 2), then the quantity of sulfuric acid needed for a reaction of one mole of aromatic substrate ( $92 \mathrm{~g}$ in the case of toluene as substrate) would approach $200 \mathrm{~g}$. For the arbitrary zeolite to be able to replace sulfuric acid directly, over $2000 \mathrm{~g}$ would be required in order to achieve a similar profile. Not only would such a quantity of zeolite be inconvenient and highly expensive for nitration of, say, toluene (92 g) with nitric acid (63 $\mathrm{g}$ if $100 \%)$, but the substrate and reagent would be completely absorbed into the pores to leave 
a dry material. It would be very difficult to ensure that all of the substrate molecules would find all of the reagent molecules, since diffusion through the pores might be limited under such circumstances. Therefore, for zeolites to be useful in nitration reactions, they cannot take on the role of water-remover and their role as proton donor must be catalytic.

At the outset of our research in this area our aim was to find an alternative to nitric acid as the source of the nitro group. If a zeolite were to have any beneficial effect, it would need to catalyse the reaction, so it should be capable of protonation to give nitronium ion, and the by-product should be less prone to quenching the nitration reaction than the water produced in the case of nitric acid. Our first candidate was benzoyl nitrate, which gives benzoic acid as the by-product (Equation 4).

$\mathrm{PhCO}_{2} \mathrm{NO}_{2}+\mathrm{H}^{+} \rightleftharpoons \mathrm{PhCO}_{2} \mathrm{H}+\mathrm{NO}_{2}^{+}$

In the absence of water, any of a range of solvents could be added to increase the mobility of the mixture and diffusion of the materials through the zeolite pores. Several zeolites were tested for beneficial effects and mordenite gave the best results of those tried. The reaction (Scheme 1) was high yielding, much more para-selective than traditional nitration reactions, and the zeolite could be recovered and re-used [31]. When a similar reaction was carried out (by others) over surfacedeactivated ZSM-11 in hexane, the para-product was obtained in even higher selectivity (98\%), though in lower yield [32-34]. Also, benzoyl nitrate is expensive to produce.

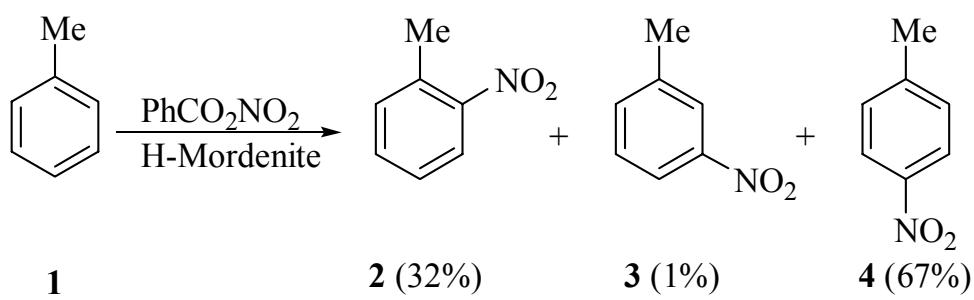

Scheme 1.

Toluene (1) has also been successfully nitrated with alkyl nitrates over zeolites. When a high silica form of ZSM-5 zeolite $(\mathrm{Si} / \mathrm{Al}=1000)$ was used and the reaction was carried out at high dilution, mononitrated toluenes were produced in $54 \%$ yield with a para/ortho ratio of 19 , though a very large 
quantity of the zeolite was required [35]. Unfortunately, a more available ZSM-5 ( $\mathrm{Si} / \mathrm{Al}=30)$ was less selective [35].

Unfortunately, therefore, none of the early para-regioselective methods involving zeolites was attractive for large-scale use. Therefore, we undertook further investigations in an attempt to develop a method that would retain the high yield and selectivity, but use inexpensive reagents and avoid the need for large quantities of solvents. Acetyl nitrate, which can be generated in situ by mixing acetic anhydride and nitric acid (Equation 5) seemed to offer a useful possibility.

$\mathrm{Ac}_{2} \mathrm{O}+\mathrm{HNO}_{3} \rightleftharpoons \mathrm{AcONO}_{2}+\mathrm{AcOH}$

Indeed, simple aromatic compounds 5 were nitrated (Scheme 2) in excellent yields (Table 1) and with high regioselectivity under mild conditions with this reagent, generated using just stoichiometric quantities of nitric acid and acetic anhydride and in the absence of any additional solvent, when zeolite $\mathrm{H} \beta$ was the catalyst [42].

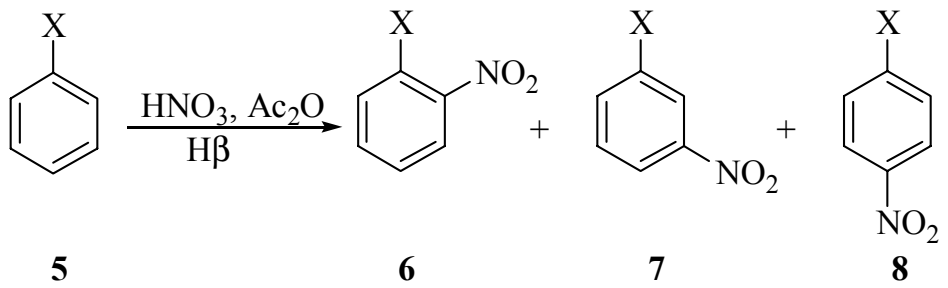

Scheme 2.

Table 1. Nitration of Simple Aromatic Compounds 5 According to Scheme 2 Using $\mathrm{HNO}_{3} / \mathrm{Ac}_{2} \mathrm{O} / \mathrm{H}^{a}$

\begin{tabular}{|l|l|l|l|l|l|}
\hline $\mathbf{X}$ & \multirow{2}{*}{$\mathbf{t}(\mathbf{m i n})$} & Yield (\%) & \multicolumn{4}{l|}{ Proportions of the isomers (\%) } \\
\cline { 4 - 6 } & & & $\mathbf{6}$ & $\mathbf{7}$ & $\mathbf{8}$ \\
\hline \hline $\mathrm{Me}$ & 30 & $>99$ & 18 & 3 & 79 \\
\hline $\mathrm{Et}$ & 10 & $>99$ & 15 & 3 & 82 \\
\hline${ }^{i} \mathrm{Pr}$ & 30 & $>99$ & 9 & 3 & 88 \\
\hline${ }^{t} \mathrm{Bu}$ & 30 & 92 & 8 & traces & 92 \\
\hline $\mathrm{F}$ & 30 & $>99$ & 6 & 0 & 94 \\
\hline $\mathrm{Cl}$ & 30 & $>99$ & 7 & 0 & 93 \\
\hline $\mathrm{Br}$ & 30 & $>99$ & 13 & 0 & 87 \\
\hline
\end{tabular}

${ }^{a} \mathrm{H} \beta(1 \mathrm{~g}), \mathrm{HNO}_{3}(35 \mathrm{mmol}$ of $90 \%), \mathrm{Ac}_{2} \mathrm{O}(53 \mathrm{mmol})$ and $\mathbf{5}(35 \mathrm{mmol})$ at room temperature for the indicated reaction time followed by distillation under reduced pressure [42]. 
The order of addition of the materials had a significant effect on the para-selectivity of the reaction. The best order involved premixing the zeolite with nitric acid, followed by addition of acetic anhydride and lastly the aromatic compound. This is consistent with the formation of acetyl nitrate predominantly within the pores of the zeolite, where reaction with the substrate then takes place.

It is clear that it is possible to nitrate toluene in essentially quantitative yield with high paraselectivity (79\%) and without recourse to expensive or relatively inaccessible reagents or to conditions (e.g. temperature and solvent) that would preclude application on a large scale. The procedure could be applied to a range of substrates of moderate activity, which are the ones that often give selectivity problems in traditional nitrations. The zeolite could be recycled, and the only by-product was acetic acid, which could be separated easily from the nitration products by distillation. These results represent the highest para-selectivities yet achieved in high yielding nitration reactions for such an extensive range of substances, and dinitro compounds are not formed in any significant amount [42]. The mechanism of the reaction has been investigated in detail by the group of Prins $[43,44]$. Their studies confirm the intermediacy of acetyl nitrate and support the view that the selectivity arises by constrictions on the transition state within the zeolite pores $[43,44]$.

Although the method described in Scheme 2 seems to meet all the criteria of a clean, green, environmentally more acceptable nitration process, commercial organisations appear reluctant to adopt the new technology. Therefore, we continue to look for alternative methods of activating selective nitration.

Aromatic compounds can also be readily nitrated more para-selectively with dinitrogen pentoxide by use of zeolite catalysis [45]. However, the process suffers several disadvantages such as the production of one mole of nitric acid per mole of product. Moreover, the reagent can only be produced using special facilities. Vapour phase nitration with nitrogen dioxide at elevated temperatures in the presence of zeolites has also been reported, but generally without particular benefits [46-49]. However, one report of nitration of chlorobenzene with nitrogen dioxide in the presence of oxygen over zeolite $\mathrm{H} \beta$ at $150{ }^{\circ} \mathrm{C}$ gave an ortho/meta/para product distribution of $3 / 1 / 96$, though the overall yield of chloronitrobenzenes was only $38 \%$ [50]. Furthermore, the method utilising $\mathrm{N}_{2} \mathrm{O}_{4}$ and oxygen can be catalysed by tris(pentane-2,4-dionato)iron(III) $\left(\mathrm{Fe}(\mathrm{acac})_{3}\right)$ in an organic solvent $[51,52]$. In principle, this could lead to a highly atom-efficient process, but it is not regioselective. Therefore, we decided to study nitration using dinitrogen tetroxide and oxygen in the presence of zeolites to see if 
we could develop a process that would be mild, high-yielding and para-selective. Fortunately, nitration of chlorobenzene with excess liquid $\mathrm{N}_{2} \mathrm{O}_{4}$ in dichloroethane over various zeolites at $0{ }^{\circ} \mathrm{C}$ in the presence of oxygen (Scheme 3, X $=\mathrm{Cl}$ ) was promising. The results obtained are recorded in Table $2[53,54]$.

4

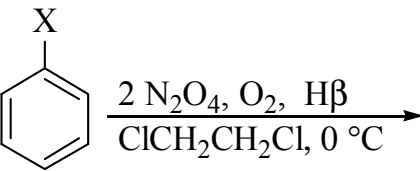

5<smiles>[X]c1cccc([N+](=O)[O-])c1</smiles>

6-8

Scheme 3.

Table 2. Nitration of Chlorobenzene According to Scheme $3(\mathrm{X}=\mathrm{Cl})^{a}$

\begin{tabular}{|l|l|l|l|l|l|l|}
\hline Catalyst (Si/Al) & t (h) & Conversion (\%) & Yield (\%) & \multicolumn{3}{|l|}{ Proportions of the isomers (\%) } \\
\cline { 5 - 7 } & & & & ortho & meta & para \\
\hline \hline- & 50 & 6 & 2 & 39 & 0 & 61 \\
\hline $\mathrm{SiO}_{2}$ & 50 & 40 & 28 & 29 & $<1$ & 70 \\
\hline $\mathrm{H} \beta(12.5)$ & 50 & 100 & 90 & 14 & $<1$ & 85 \\
\hline $\mathrm{Na} \beta(12)$ & 50 & 100 & 96 & 15 & 0 & 85 \\
\hline $\mathrm{K} \beta(12)$ & 50 & 97 & 92 & 21 & 0 & 79 \\
\hline $\mathrm{NH}_{4} \beta(12.5)$ & 50 & 76 & 70 & 30 & 1 & 69 \\
\hline $\mathrm{HY}(30)$ & 50 & 100 & 91 & 16 & 2 & 82 \\
\hline $\mathrm{NaY}(28)$ & 50 & 100 & 91 & 16 & 1 & 83 \\
\hline $\mathrm{H}-M o r d e n i t e(10.5)$ & 50 & 36 & 28 & 27 & 0 & 73 \\
\hline $\mathrm{HZSM}-5(50)$ & 72 & 44 & 42 & 28 & 2 & 70 \\
\hline HZSM-5 (150) & 72 & 48 & 32 & 20 & $<1$ & 79 \\
\hline
\end{tabular}

${ }^{a}$ Catalyst $(1 \mathrm{~g})$, chlorobenzene $(10 \mathrm{mmol}), 1,2$-dichloroethane $(30 \mathrm{ml})$ and $\mathrm{N}_{2} \mathrm{O}_{4}(c a .10 \mathrm{ml})$ under oxygen at $0{ }^{\circ} \mathrm{C}$ for the indicated reaction time $[53,54]$.

Zeolites $\mathrm{H} \beta$ and $\mathrm{Na} \beta$ produced the greatest selectivity for para-chloronitrobenzene $(85 \%)$ and among the highest yields (90 and 96\%). Therefore, the reaction over $\mathrm{H} \beta$ was applied to a range of other aromatic substrates 5 (Scheme 3) to give excellent yields of the mononitrated products 6-8 with moderate para-selectivities (Table 3) [53,54].

Table 3. Nitration of Simple Aromatic Compounds 5 According to Scheme $3^{a}$

\begin{tabular}{|l|l|l|l|l|l|l|}
\hline $\mathbf{X}$ & $\mathbf{t}(\mathbf{h})$ & Conversion (\%) & Yield (\%) & \multicolumn{4}{|l|}{ Proportions of the isomers (\%) } \\
\cline { 5 - 7 } & & & & $\mathbf{6}$ & $\mathbf{7}$ & $\mathbf{8}$ \\
\hline \hline $\mathrm{Me}$ & 24 & 100 & 85 & 53 & 2 & 45 \\
\hline $\mathrm{F}$ & 48 & 100 & 95 & 7 & 0 & 93 \\
\hline $\mathrm{Cl}$ & 48 & 98 & 95 & 14 & $<1$ & 85 \\
\hline $\mathrm{Br}$ & 48 & $>99$ & 94 & 22 & $<1$ & 77 \\
\hline $\mathrm{I}$ & 48 & 99 & 95 & 37 & 1 & 62 \\
\hline
\end{tabular}

${ }^{a} \mathrm{H} \beta(1 \mathrm{~g}), \mathbf{5}(10 \mathrm{mmol}), 1,2$-dichloroethane $(30 \mathrm{ml})$ and $\mathrm{N}_{2} \mathrm{O}_{4}(c a .10 \mathrm{ml})$ under oxygen at $0{ }^{\circ} \mathrm{C}$ for the indicated reaction time $[53,54]$. 
The method represented a potentially clean synthesis of halogenonitrobenzenes using an easily recycled catalyst. However, at this point the reactions were not as selective as we wanted, and involved a large excess of dinitrogen tetroxide, a halogenated solvent, cooling and a reaction time of $48 \mathrm{~h}$. Therefore, we studied the reaction further in order to attempt to find ways of overcoming the remaining disadvantages.

Work by the Suzuki group showed that better selectivities for the production of para-isomers could be achieved at low conversion using the substrate as its own solvent in the liquid phase [55]. It seemed that the need for cooling could be removed by use of an autoclave to contain the dinitrogen tetroxide, and this would also allow a higher oxygen or air pressure. Therefore, a detailed study was carried out of a solvent-free reaction, in the presence of air in an autoclave capable of withstanding a modest pressure. Indeed, in this way a series of substrates $\mathbf{5}$ could be nitrated to give high yields, with reasonable para-selectivities (Table 4), using only the stoichiometric quantity of dinitrogen tetroxide, using air instead of oxygen, and under mild conditions (ambient temperature and a modest pressure) [54,56]. Unfortunately, the stoichiometry is not as indicated in Scheme $\mathbf{3}$, but instead results in production of one mole of nitric acid for each 3 moles of product (Scheme 4). This disadvantage would need to be overcome in order to make the process really attractive.

3<smiles>[X]c1ccccc1</smiles>

$2 \mathrm{~N}_{2} \mathrm{O}_{4}$, air, $\mathrm{H} \beta$, RT autoclave, $200 \mathrm{psi} 3$

5<smiles>[X]c1cccc([N+](=O)[O-])c1</smiles>

6-8

Scheme 4 .

Table 4. Nitration of Simple Aromatic Compounds 5 According to Scheme $4^{a}$

\begin{tabular}{|l|l|l|l|l|l|l|}
\hline $\mathbf{X}$ & $\mathbf{t}(\mathbf{h})$ & Conversion (\%) & Yield (\%) & \multicolumn{3}{|l|}{ Proportions of the isomers (\%) } \\
\cline { 5 - 7 } & & & & $\mathbf{6}$ & $\mathbf{7}$ & $\mathbf{8}$ \\
\hline \hline $\mathrm{Me}$ & 24 & 86 & 76 & 50 & 3 & 47 \\
\hline $\mathrm{F}$ & 16 & 100 & 95 & 9 & $<1$ & 91 \\
\hline $\mathrm{Cl}$ & 14 & 100 & 97 & 15 & $<1$ & 84 \\
\hline $\mathrm{Br}$ & 14 & 97 & 90 & 19 & $<1$ & 80 \\
\hline
\end{tabular}

${ }^{a} \mathrm{H} \beta(3 \mathrm{~g}), 5(33 \mathrm{mmol})$ and $\mathrm{N}_{2} \mathrm{O}_{4}(c a .1 .4 \mathrm{ml})$ under $200 \mathrm{psi}$ air pressure at room temperature for the indicated reaction time $[54,56]$. 
Under the conditions described in Table 4 the reaction is rather slow, but simply raising the temperature to $30-40{ }^{\circ} \mathrm{C}$ in the sealed system used can reduce the required reaction period dramatically. Therefore, only two remaining obstacles prevent this reaction from fulfilling all the desired criteria. One is the relatively low para-selectivity (though already better than for traditional methods). The other is the production of a modest amount of nitric acid as by-product, which can deactivate the zeolite by adsorption or reaction, limits the efficiency of usage of the dinitrogen tetroxide and could lead to plant corrosion. We continue to search for ways to overcome these remaining disadvantages, but we have recently experienced two unexplained exotherms within the autoclave. We have suspended further work on this approach until we can understand and overcome this problem.

One other approach is worthy of note, though it is not one we have yet pursued ourselves. This involves using nitric acid as the reagent, but removing water by azeotropic distillation as the reaction proceeds [38-40]. Therefore, a modest amount of zeolite can be used in a catalytic way. Higher temperatures and longer reaction times are needed than in the approaches we have followed, and yields and selectivities tend to be lower, particularly than those obtained with nitric acid/acetic anhydride. Nevertheless, progress has been made and the method has the advantages of simplicity and cheap reagents.

\subsection{Selective Nitration of Deactivated Substrates}

Normally, the nitration of deactivated compounds (and therefore the polynitration of toluene) is carried out using aggressive nitric acid-oleum mixtures. The dinitration of toluene with mixed acids produces 2,4- and 2,6-dinitrotoluenes in a ratio of 4:1, from which 2,4-dinitrotoluene is isolated for the manufacture of toluene di-isocyanate (TDI), which is used in the manufacture of polyurethanes, and toluenediamine. Zirconium and hafnium derivatives catalyse nitration of 2-nitrotoluene (2), but the ratio of 2,4-:2,6-dinitrotoluene is modest (66:34) [59]. Dinitration of toluene using claycop (copper nitrate on K10 clay), acetic anhydride and nitric acid in the presence of tetrachloromethane has produced dinitrotoluenes in a yield of $85 \%$ with a ratio of 2,4-:2,6-dinitrotoluene of 9:1 [60]. This method, however, requires a large excess of nitric acid, the use of an unacceptable solvent and long reaction times. The direct dinitration of toluene to 2,4-dinitrotoluene using nitric acid over zeolite $\mathrm{H} \beta$ catalyst, with azeotropic removal of water, has been reported to give a 2,4:2,6-dinitrotoluene ratio of 14 $[57]$. 
After our success in nitrating moderately active monosubstituted benzenes with the $\mathrm{HNO}_{3} / \mathrm{Ac}_{2} \mathrm{O} / \mathrm{H} \beta$ system [42], we decided to try the use of this system for nitration of deactivated substrates. However, the reactions were too slow to be useful and we decided to look at trifluoroacetyl nitrate as a more powerful reagent. Although trifluoroacetyl nitrate is known to be more active than acetyl nitrate, it has not been widely used in nitration reactions $[25,26]$. Nitrobenzene had been successfully nitrated using fuming nitric acid and trifluoroacetic anhydride (TFAA) in equimolar proportions at $45-55^{\circ} \mathrm{C}$ [61]. Our initial studies involved nitration of 4-nitrotoluene (4), which was nitrated exclusively to give 2,4-dinitrotoluene (9). We found that a TFAA/ $\mathrm{HNO}_{3}$ mixture was active enough to nitrate this substrate in high yield at room temperature without the need for a zeolite. For nitration of 2-nitrotoluene (2), there were two main products, 2,4-dinitrotoluene (9) and 2,6dinitrotoluene (10). Again, we found that the TFAA $/ \mathrm{HNO}_{3}$ mixture alone was active enough to effect nitration. However, the presence of zeolite $\mathrm{H} \beta$ improved regioselectivity for the 2,4-isomer slightly (9:10 ratio was 3:1 compared to 2:1 without zeolite), although it did not have much effect on the overall reaction rate or product yield. It appeared that the free solution reaction was so fast that most of the reactants did not have time to diffuse into the pore system and so reaction occurred primarily in free solution or at the external surface of the zeolite.

In order to slow down the overall reaction we added acetic anhydride as a diluent, thereby giving the zeolite a better chance to exert an influence over the reaction. Indeed, this led to a slower reaction and zeolite $\mathrm{H} \beta$ then exerted a greater influence over both rate and selectivity. In the absence of zeolite the yield of $\mathbf{9}$ and $\mathbf{1 0}$ from 2-nitrotoluene (2) after $2 \mathrm{~h}$ at $-10{ }^{\circ} \mathrm{C}$ was only $16 \%$ and the 9:10 ratio was the usual 2:1. However, with zeolite $\mathrm{H} \beta$ ( $1 \mathrm{~g}$ for $17.5 \mathrm{mmol}$ of 2 ) present, the yield increased to $99 \%$ and the 9:10 ratio to 17:1 (Scheme 5) [58]. 4-Nitrotoluene (4) could be also nitrated with the optimised system used for 2-nitrotoluene (2), but the reaction was much slower. Therefore, for direct dinitration of toluene it would be necessary to minimise the amount of the diluent used.

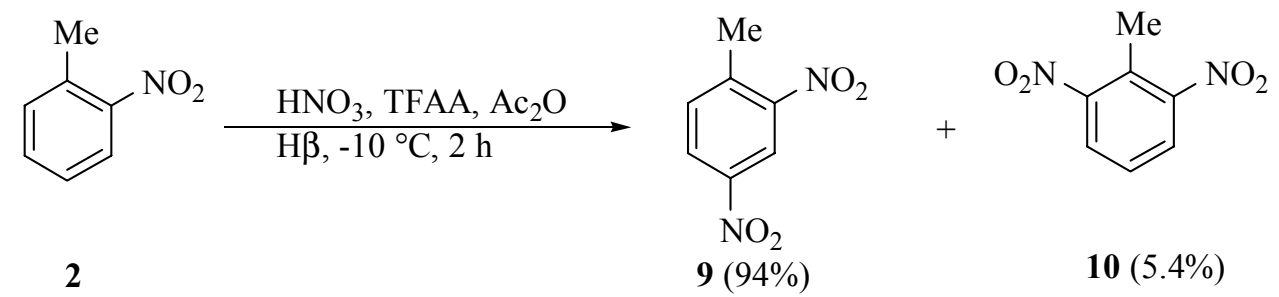

Scheme 5. 
The single step nitration of toluene (1) using two equivalents of the $\mathrm{HNO}_{3} / \mathrm{TFAA} / \mathrm{Ac}_{2} \mathrm{O}$ system produced dinitrotoluenes $\mathbf{9}$ and $\mathbf{1 0}$ in almost quantitative yield with high para-selectivity (9:10 $=24: 1$ ) using $1 \mathrm{~g}$ of $\mathrm{H} \beta$, and the selectivity was $14: 1$ even when only $0.5 \mathrm{~g}$ of $\mathrm{H} \beta$ was used [58]. Excellent though these results were, the ratio of 9:10 was less than would be predicted if the first step were to give 2- and 4-nitrotoluenes in the published ratio for the $\mathrm{HNO}_{3} / \mathrm{Ac}_{2} \mathrm{O} / \mathrm{H} \beta$ system (ca. 4:1), and the subsequent second nitration step were to proceed as described above. 4-Nitrotoluene (4) should give only 2,4-dinitrotoluene (9), while 2-nitrotoluene (2) should give $\mathbf{9}$ and $\mathbf{1 0}$ in a 17:1 ratio. In this case the ratio expected for the overall process would be in the region of $98: 2$ to $99: 1$. It seemed likely that the problem was a less selective first step using trifluoroacetic anhydride. Therefore, a two-step nitration process was investigated.

The two-step nitration process, in which only acetic anhydride and zeolite $\mathrm{H} \beta$ were used in the first step and extra $\mathrm{H} \beta$ zeolite and trifluoroacetic anhydride were added in the second step (Scheme 6), improved the para-regioselectivity to a 9:10 ratio of 70:1, and a quantitative yield was obtained after 2 $\mathrm{h}$ at around $-10{ }^{\circ} \mathrm{C}$ [58]. Pure 2,4-dinitrotoluene (9) could be isolated in $90 \%$ yield from this reaction simply by filtration of the zeolite, concentration of the mother liquor, and recrystallisation from acetone.

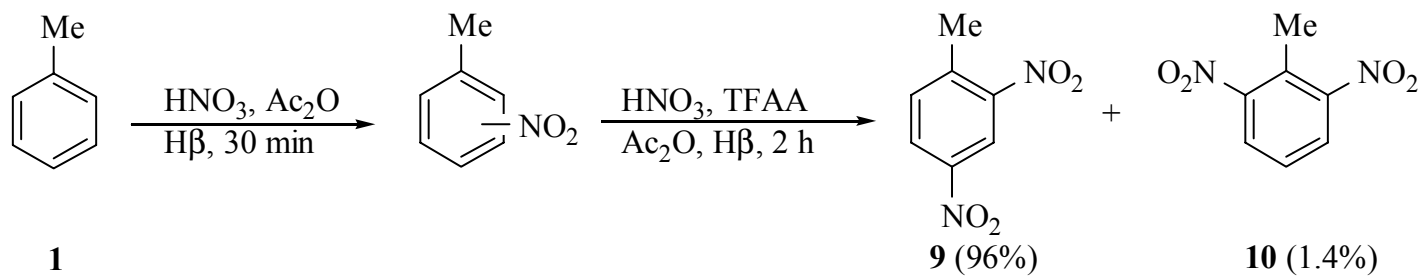

Scheme 6.

A series of deactivated monosubstituted benzenes 5 (Scheme 2) that contain meta-directing deactivating groups $\left(\mathrm{NO}_{2}, \mathrm{CO}_{2} \mathrm{H}, \mathrm{CN}\right)$ was subjected to the $\mathrm{HNO}_{3} / \mathrm{TFAA} / \mathrm{H} \beta$ system. The results obtained are recorded in Table 5. Reasonable yields of mononitrated products were obtained under the standard reaction conditions, and individual optimisation of the reaction conditions would probably allow quantitative conversion in such cases. In comparison to mixed acid nitration, there was some 
increase in the amount of both the ortho- and para-isomers for two of the substrates, but meta-nitro products were still vastly predominant in all cases [58].

Table 5. Nitration of Simple Aromatic Compounds 5 According to Scheme 2 Using $\mathrm{HNO}_{3} / \mathrm{TFAA} / \mathrm{H}^{a}{ }^{a}$

\begin{tabular}{|l|l|l|l|l|}
\hline $\mathbf{X}$ & \multirow{2}{*}{ Yield (\%) } & Proportions of the isomers (\%) & \multicolumn{2}{l|}{} \\
\cline { 3 - 6 } & & $\mathbf{6}$ & 7 & $\mathbf{8}$ \\
\hline \hline $\mathrm{NO}_{2}$ & 72 & 5 & 88 & 7 \\
\hline $\mathrm{CO}_{2} \mathrm{H}$ & 86 & 2 & 97 & 1 \\
\hline $\mathrm{CN}$ & 54 & 13 & 74 & 13 \\
\hline
\end{tabular}

${ }^{a} \mathrm{H} \beta(1 \mathrm{~g}), 5(17.5 \mathrm{mmol}), \mathrm{HNO}_{3}(17.5 \mathrm{mmol}$ of $90 \%)$ and TFFA $(17.5 \mathrm{mmol})$ at $-10{ }^{\circ} \mathrm{C}$ for $2 \mathrm{~h}[58]$.

The same series of deactivated monosubstituted benzenes 5 (Scheme 2) was then subjected to the $\mathrm{HNO}_{3} / \mathrm{TFAA} / \mathrm{Ac}_{2} \mathrm{O} / \mathrm{H} \beta$ system. The results obtained are recorded in Table 6 . There was, in most cases, an increase in the proportion of the para-isomer, to $19 \%$ in the case of benzonitrile, presumably as a result of shape-selectivity imposed on the transition state. In the case of benzoic acid, there was also an increase in the proportion of the ortho-isomer (11\%), possibly resulting from rearrangement of benzoyl nitrate formed in situ. However, in all cases the meta-isomer was still vastly predominant [58].

Table 6. Nitration of Simple Aromatic Compounds 5 According to Scheme 2 Using $\mathrm{HNO}_{3} / \mathrm{TFAA} / \mathrm{Ac}_{2} \mathrm{O} / \mathrm{H}^{a}$

\begin{tabular}{|l|l|l|l|l|}
\hline $\mathbf{X}$ & \multirow{2}{*}{ Yield (\%) } & \multicolumn{4}{|l|}{ Proportions of the isomers (\%) } \\
\cline { 3 - 5 } & & $\mathbf{6}$ & $\mathbf{7}$ & $\mathbf{8}$ \\
\hline \hline $\mathrm{NO}_{2}$ & 25 & 2 & 91 & 7 \\
\hline $\mathrm{CO}_{2} \mathrm{H}$ & 74 & 11 & 79 & 10 \\
\hline $\mathrm{CN}$ & 17 & 10 & 71 & 19 \\
\hline
\end{tabular}

${ }^{a} \mathrm{H} \beta(1 \mathrm{~g}), 5(17.5 \mathrm{mmol}), \mathrm{HNO}_{3}(17.5 \mathrm{mmol}$ of $90 \%)$, TFFA $(17.5 \mathrm{mmol})$ and $\mathrm{Ac}_{2} \mathrm{O}(3.5 \mathrm{ml}, 37 \mathrm{mmol})$ at $-10{ }^{\circ} \mathrm{C}$ for $2 \mathrm{~h} \mathrm{[58].}$

\section{REGIOSELECTIVE DIALKYLATION OF NAPHTHALENE}

There is considerable interest in the use of zeolites to control alkylation of naphthalene [6276]; as the use of shape selective zeolites as non-conventional Friedel-Crafts catalysts would be very interesting from the economic and environmental points of view. One convenient process for preparation of naphthalene-2,6-dicarboxylic acid would involve selective dimethylation of naphthalene followed by oxidation. Unfortunately, simple double methylation of naphthalene is not easy to control and can result in up to ten dimethylnaphthalene isomers, which need separation [77]. 
Although some improvements in selectivity had been made by use of zeolites, there was still difficulty in obtaining the 2,6-isomer in preference to the 2,7-isomer. For example, it was found that $\beta$-selectivity could be achieved over zeolite HZSM-5, whereas non-selective alkylation was seen over the larger pore H-Mordenite (HM) and HY zeolites [78]. However, even using HZSM-5 a poor yield of the 2,6-isomer was obtained and the ratio of 2,6/2,7 isomers was approximately 1 .

Isopropylation of naphthalene with propene [79], isopropyl alcohol [80-84] and isopropyl bromide [85] as reagents, had been studied using a variety of zeolites. In this case, $\beta, \beta$-selectivities of over $75 \%$, with a 2,6/2,7 ratio of approximately 2 , have been reported using HM [86], and the best isopropylation procedure gave a 54\% yield of 2,6-di-isopropylnaphthalene with a 2,6/2,7 ratio of 4 [86]. Cyclohexyl and tert-butyl groups are even bulkier than the isopropyl group. The best reported cyclohexylation of naphthalene makes use of HY zeolite, and results in a $19 \%$ yield of the corresponding 2,6-dicyclohexylnaphthalene, with a 2,6/2,7 ratio of 1.2 [87]. The same authors also reported a $23 \%$ yield of 2,6-di-tert-butylnaphthalene, with a 2,6/2,7 ratio of 5.9, with the added advantage of easy separation of the 2,6-isomer by crystallisation $[88,89]$. The tert-butylation result suggested that it might be possible to achieve highly selective production of a 2,6-dialkylnaphthalene. Therefore, we undertook a detailed study of the alkylation reaction, especially tert-butylation, to see if improvements could be made in the yield and selectivity for the 2,6-isomer.

Initially, a range of different zeolites was screened for efficacy in the tert-butylation of naphthalene (11) in cyclohexane, under conditions as close as possible to those used by Moreau and co-workers $[88,89]$. The major products of the tert-butylation reaction were 2-tert-butylnaphthalene (12), 2,6-di-tert-butynaphthalene (13) and 2,7-di-tert-butylnaphthalene (14) (Scheme 7) [90]. Some of the results obtained are recorded in Table 7.

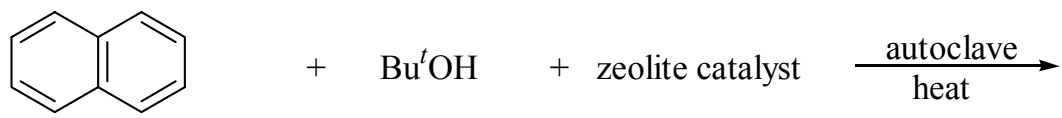

11<smiles>Brc1ccc2cc(Br)ccc2c1</smiles>

Scheme 7. 
Table 7. tert-Butylation of Naphthalene (11) Over Various Zeolites According to Scheme $7^{a}$

\begin{tabular}{|c|c|c|c|c|c|}
\hline \multirow[t]{2}{*}{ Zeolite } & \multirow[t]{2}{*}{ Conversion (\%) } & \multicolumn{3}{|c|}{ Yields (\%) } & \multirow[t]{2}{*}{$13 / 14$ ratio $^{b}$} \\
\hline & & 12 & 13 & 14 & \\
\hline$\overline{\mathrm{HYY}}$ & 89 & 39 & 33 & 12 & 2.7 \\
\hline $\mathrm{H} \beta$ & 49 & 46 & 2 & 2 & 1.1 \\
\hline HM & 24 & 22 & 2 & - & - \\
\hline HZSM-5 & 0 & - & - & - & - \\
\hline
\end{tabular}

${ }^{a} 18 \mathrm{~h}$ stirred autoclave reaction at $160{ }^{\circ} \mathrm{C}$; zeolite $(0.5 \mathrm{~g})$, cyclohexane $(100 \mathrm{ml}), \mathbf{1 1}(10 \mathrm{mmol})$ and $\mathrm{Bu}^{t} \mathrm{OH}(20$ $\mathrm{mmol}$ [90]. ${ }^{b}$ Ratio calculated from pre-rounded yield figures.

The trends in the results were consistent with the reported ones [88,89], where direct comparison was possible. The minor variations in the absolute results can be understood in terms of the use of different zeolite samples and a different autoclave with different dimensions, resulting in a different self-generated pressure, and different temperature control. It was found that zeolite HY was the most active solid and zeolite $\mathrm{H} \beta$ was essentially non-selective for the production of $\mathbf{1 3}$ over $\mathbf{1 4}$ (13/14 ratio of 1.1) [90]. In addition, we found that HZSM-5 gave no reaction, presumably because the pores were too small to allow the reaction to occur. However, attention was attracted mostly by the results with HM. Although only a $24 \%$ conversion of naphthalene and a $2 \%$ yield of di-tertbutylnaphthalene were achieved with $\mathrm{HM}(\mathrm{Si} / \mathrm{Al} \mathrm{10)}$, it was promising that the only dialkyl isomer detected under these conditions was 13. With HM ( $\mathrm{Si} / \mathrm{Al} \mathrm{17.5),} \mathrm{a} \mathrm{naphthalene} \mathrm{conversion} \mathrm{of} 31 \%$ and a $6.4 \%$ yield of dialkyl products with a $\mathbf{1 3 / 1 4}$ ratio of 14 were observed [90]. Therefore, we undertook a more detailed study of the reaction with HM as a catalyst in the hope of enhancing the conversion into dialkylnaphthalenes while retaining the higher selectivity.

We attempted to increase the conversion into desirable product by using more forcing conditions (increased reaction time and temperature) and by adding more zeolite and/or tert-butyl alcohol. It was found that doubling the amount of catalyst to $1.0 \mathrm{~g}$ in the presence of $\mathrm{HM}$ ( $\mathrm{Si} / \mathrm{Al} \mathrm{10}$ ) increased the conversion by $12 \%$ and the yield of di-tert-butylnaphthalenes by $4 \%$. Also, it was possible to identify the 2,7-isomer $\mathbf{1 4}$ in the reaction mixture and a $\mathbf{1 3 / 1 4}$ ratio of 17.3 could be seen, already a significant improvement over all previously reported selectivities [90]. When the temperature was increased to $200{ }^{\circ} \mathrm{C}$, the conversion and the yield of $\mathbf{1 3}$ were increased from 40 to $52 \%$ and from 5 to $10 \%$, respectively. However, when the temperature was increased further to $220{ }^{\circ} \mathrm{C}$, both conversion and yield of $\mathbf{1 3}$ were seen to fall, to $42 \%$ and $8 \%$, respectively (Table 8) [90]. 
Table 8. tert-Butylation of Naphthalene (11) According to Scheme 7 Over HM (Si/Al 10) Under Various Temperatures ${ }^{a}$

\begin{tabular}{|l|l|l|l|l|l|}
\hline \multirow{2}{*}{$\mathbf{T}^{\circ} \mathbf{C}$} & Conversion (\%) & Yields (\%) & \multicolumn{1}{|l|}{$\mathbf{1 3}^{\mathbf{0}} \mathbf{1 4}$ ratio $^{b}$} \\
\cline { 3 - 5 } & & $\mathbf{1 2}$ & $\mathbf{1 3}$ & $\mathbf{1 4}$ & \\
\hline \hline 140 & 40 & 33 & 5 & 0.2 & 22.8 \\
\hline 160 & 43 & 34 & 8 & 0.5 & 16.4 \\
\hline 180 & 47 & 38 & 9 & 0.6 & 13.4 \\
\hline 200 & 52 & 41 & 10 & 1 & 9.5 \\
\hline 220 & 42 & 31 & 8 & 1 & 6.4 \\
\hline
\end{tabular}

${ }^{a} 18 \mathrm{~h}$ stirred autoclave reaction; HM $(2 \mathrm{~g})$, cyclohexane $(100 \mathrm{ml}), 11(10 \mathrm{mmol})$ and $\mathrm{Bu}^{t} \mathrm{OH}(20 \mathrm{mmol})[90]$.

${ }^{b}$ Ratio calculated from pre-rounded yield figures.

Increasing the amount of tert-butyl alcohol up to $80 \mathrm{mmol}$ brought about increases in both conversion and the yield of $\mathbf{1 3}$, although excessive amounts (more than $80 \mathrm{mmol}$ ) caused both to fall. However, the $\mathbf{1 3 / 1 4}$ ratio was seen to increase with increasing tert-butyl alcohol without reaching a maximum (Table 9) [90].

Table 9. tert-Butylation of Naphthalene (11) According to Scheme 7 Over HM (Si/Al 10) Using Various Quantities of tert-Butyl Alcohol ${ }^{a}$

\begin{tabular}{|l|l|l|l|l|l|}
\hline \multirow{2}{*}{$\begin{array}{l}\text { tert-Butyl alcohol } \\
(\mathbf{m m o l})\end{array}$} & \multirow{2}{*}{ Conversion (\%) } & \multicolumn{3}{|l|}{ Yields (\%) } & \multirow{2}{*}{${\text { 13/14 } \text { ratio }^{b}}^{b}$} \\
\cline { 3 - 5 } & & $\mathbf{1 2}$ & $\mathbf{1 3}$ & $\mathbf{1 4}$ & \\
\hline \hline 20 & 54 & 40 & 12 & 1 & 10.9 \\
\hline 40 & 56 & 40 & 16 & 0.5 & 33.9 \\
\hline 80 & 57 & 38 & 19 & 0.4 & 44.2 \\
\hline 160 & 50 & 37 & 12 & 0.2 & 75.6 \\
\hline 530 & 21 & 19 & 3 & - & - \\
\hline
\end{tabular}

${ }^{a} 18 \mathrm{~h}$ stirred autoclave reaction at $180{ }^{\circ} \mathrm{C}$; $\mathrm{HM}(4 \mathrm{~g})$, cyclohexane $(100 \mathrm{ml}), 11(10 \mathrm{mmol})$ and $\mathrm{Bu}{ }^{t} \mathrm{OH}[90]$.

${ }^{b}$ Ratio calculated from pre-rounded yield figures.

The general trend on increasing the reaction time was an increase in the conversion and yield of 13, with little variation in the $\mathbf{1 3} / \mathbf{1 4}$ ratio. However, the conversion increased from $54 \%$ to only $66 \%$ and the yield of $\mathbf{1 3}$ from $14 \%$ to only $22 \%$ on varying the reaction time from 1 to $24 \mathrm{~h}$. Clearly, the majority of the reaction occurred within the first hour and only an extra $12 \%$ conversion occurred in the next $23 \mathrm{~h}$. Therefore, $1 \mathrm{~h}$ is a more suitable reaction time [90].

Further studies were conducted using different pressures; tert-butylating species; solvent; stoichiometery; $\mathrm{Si} / \mathrm{Al}$ ratio of the zeolite HM; and modes of addition. We found that the optimum conditions for maximising the yield of $\mathbf{1 3}$ while retaining selectivity over this zeolite involved successive $1 \mathrm{~h}$ autoclave reactions at $180{ }^{\circ} \mathrm{C}$, using $\mathrm{HM}(4 \mathrm{~g})$, tert-butyl alcohol $(80 \mathrm{mmol})$ and cyclohexane (10 ml) for each stage and an initial $10 \mathrm{mmol}$ of naphthalene (Table 10) [90]. 


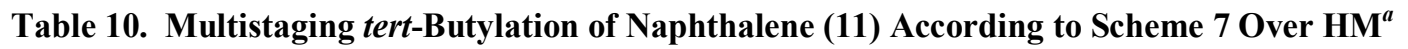

\begin{tabular}{|l|l|l|l|l|l|l|}
\hline Stage & \multirow{2}{*}{ HM (Si/Al) } & Conversion (\%) & \multicolumn{2}{|l|}{ Yields (\%) } & \multirow{2}{*}{$\mathbf{1 3}^{\mathbf{1 4}}$} \\
\cline { 4 - 6 } & & & $\mathbf{1 2}$ & $\mathbf{1 3}$ & $\mathbf{1 4}$ & \\
\hline \hline 1 & 10 & 72 & 21 & 43 & 1 & 37.1 \\
\hline $2^{c}$ & 10 & 92 & 13 & 63 & 2 & 34.8 \\
\hline $3^{c}$ & 10 & 96 & 13 & 62 & 3 & 25.1 \\
\hline 1 & 17.5 & 84 & 18 & 50 & 0.8 & 58.5 \\
\hline $2^{c}$ & 17.5 & 96 & 10 & 60 & 1 & 50.6 \\
\hline $3^{c}$ & 17.5 & 96 & 8 & 60 & 1 & 44.7 \\
\hline
\end{tabular}

${ }^{a} 1 \mathrm{~h}$ stirred autoclave reaction at $180{ }^{\circ} \mathrm{C}$; $\mathrm{HM}(4 \mathrm{~g})$, cyclohexane $(10 \mathrm{ml}), \mathbf{1 1}(10 \mathrm{mmol})$ and $\mathrm{Bu}^{t} \mathrm{OH}(80 \mathrm{mmol})$

[90]. ${ }^{b}$ Ratio calculated from pre-rounded yield figures. ${ }^{c}$ The yield of a by-product became significant $(>10 \%)$.

Under these conditions, a $50 \%$ yield of $\mathbf{1 3}$ and a $\mathbf{1 3} / \mathbf{1 4}$ ratio of 58.5 were achieved after the first stage over HM (17.5), a $60 \%$ yield with a 50.6 ratio after the second stage, and a $60 \%$ yield with a 44.7 ratio after the third stage. Approximately $85 \%$ of $\mathbf{1 3}$ present in the product mixture could be isolated in pure form by concentrating the reaction mixture following the optimum reaction and then allowing the product to crystallise. Purification was obtained by crystallisation from hot ethanol. Separation of the remaining $\mathbf{1 3}$ ( $\mathrm{ca} .15 \%$ of the total) was obtained by kugelrohr distillation under reduced pressure.

For comparison, reactions with $\mathrm{HY}$ and $\mathrm{H} \beta$ were conducted under the conditions optimised for HM, though only for a single stage reaction. The actual yield of $\mathbf{1 3}$ was significantly higher with HM (17.5) (50\%) than with HM (10) (43\%), HY (37\%) or H $\beta(19 \%)[90]$.

One of the reasons for studying the tert-butylation reaction in detail was the easy separation of the desired product. The cyclohexylation of naphthalene also benefits from this easy separation of the 2,6-isomer from the product mixture. Cyclohexylation of naphthalene (11) with various cyclohexylating agents over zeolite catalysts ( $\mathrm{Scheme} \mathbf{8}, \mathrm{R}=\mathrm{C}_{6} \mathrm{H}_{11}$ ) was also investigated [90].

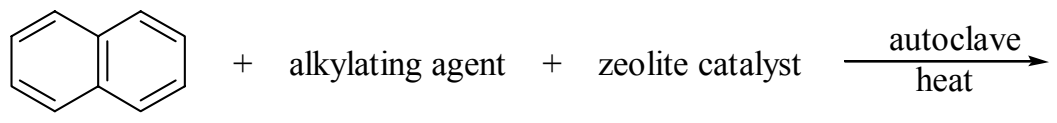

11<smiles>[R]c1ccc2ccccc2c1</smiles>

15<smiles>[R]c1ccc2cc([R])ccc2c1</smiles>

16<smiles>[R]c1ccc2ccc([R])cc2c1</smiles>

17

\section{Scheme 8.}


It was found that cyclohexanol was less $\beta, \beta$-selective than cyclohexene and cyclohexyl bromide. $\mathrm{H} \beta$ gave only $18 \%$ conversion and $2 \%$ of dicyclohexylnaphthalenes, and akin to the $\mathrm{H} \beta$ catalysed tert-butylation reaction, failed to achieve any selectivity (2,6-/2,7- isomer ratio of 1$)$. Unsurprisingly, HM did not give a reaction under those conditions, presumably more forcing conditions being required for a reaction to occur. In addition, no reaction was achieved over HZSM-5, presumably due to the pores being too small to allow the reaction to occur [90].

Several other alkylations of naphthalene (11) at $180^{\circ} \mathrm{C}$, using $\mathrm{HM}(10)$ and various alkylating agents in cyclohexane (Scheme $\mathbf{8}, \mathrm{R}=\mathrm{Pr}^{i}, \mathrm{Bu}^{n}, \mathrm{Bu}^{i}, \mathrm{Bu}^{\text {sec }}$ ) have also been investigated (Table 11). With isopropyl alcohol as alkylating agent, a naphthalene conversion of $13 \%$ was achieved. The yield of 2,6-dialkylnaphthalene $\mathbf{1 6}$ was only $0.5 \%$, although a selectivity of 2.2 was achieved, which is consistent with results obtained by others using $\mathrm{HM}$ with a moderate $\mathrm{Si} / \mathrm{Al}$ ratio [79]. For the primary alcohols (1-butanol and isobutyl alcohol) it was not surprising that naphthalene conversions and selectivities were poor ( 3 and $5 \%$ yields, respectively, with selectivity of 1.0 and 1.5 , respectively) [90]. It is clear that the carbocation formed has a major effect on the reaction rate and selectivity.

Table 11. Alkylation of Naphthalene (11) Using Various Alkylating Agents According to Scheme 8 Over HM (Si/Al 10) ${ }^{a}$

\begin{tabular}{|l|l|l|l|l|l|l|}
\hline Alkylating agent & \multirow{2}{*}{$\mathbf{R}$} & \multirow{2}{*}{ Conversion (\%) } & \multicolumn{2}{|l|}{ Yields (\%) } & \multirow{2}{*}{$\mathbf{1 6}^{\prime}$} \\
\cline { 3 - 6 } & & & $\mathbf{1 5}$ & $\mathbf{1 6}$ & $\mathbf{1 7}$ ratio $^{b}$ \\
\hline \hline Isopropyl alcohol & $\mathrm{Pr}^{i}$ & 13 & 12 & 0.5 & 0.2 & 2.2 \\
\hline 1-Butanol & $\mathrm{Bu}^{n}$ & 3 & 2 & 0.1 & 0.1 & 1.0 \\
\hline Isobutyl alcohol & $\mathrm{Bu}^{i}$ & 5 & 3 & 0.3 & 0.2 & 1.5 \\
\hline 2-Butanol & $\mathrm{Bu}^{\text {sec }}$ & 31 & 24 & 4 & 1 & 3.3 \\
\hline
\end{tabular}

${ }^{a} 1 \mathrm{~h}$ stirred autoclave reaction at $180{ }^{\circ} \mathrm{C} ; \mathrm{HM}(4 \mathrm{~g})$, cyclohexane $(10 \mathrm{ml})$ and $\mathbf{1 1}(10 \mathrm{mmol})$, alkylating agent $(10$ mmol) [90]. ${ }^{b}$ Ratio calculated from pre-rounded yield figures.

tert-Butyl alcohol has therefore been found to be the most active and most selective reagent, although it should be recognized that the reaction conditions are optimised for this reagent and not for the others. However, it is promising that moderate selectivity can also be achieved with the secondary alcohol, 2-butanol (31\% conversion with a 2,6-/2,7- isomer ratio of 3.3) [90].

Although this method is easily the most selective yet discovered for production of a 2,6-dialkylnaphthalene, it may be difficult to oxidise the tert-butyl groups to carboxyl groups. Also, there would be a loss of six carbon atoms during this process, which is wasteful. Therefore, there is still room for considerable improvement in the clean and selective synthesis of naphthalene-2,6dicarboxylic acid. These reaction systems are extremely complex, involving several phases (solid, 
liquid and gas); reactions may take place inside or outside of the zeolite pores; competing reactions, some of which may involve equilibria, are possible; and the generation of by-products (e.g. water, alkene) that may themselves influence the reaction course must also be considered. It would be of interest to study them in greater detail in order better to understand the mechanism and the role played by such parameters as added water or higher pressure.

\section{REGIOSELECTIVE ACYLATION OF AROMATIC COMPOUNDS}

Acylation of aromatic compounds over zeolite catalysts to produce the corresponding paraacylated aromatics selectively has been extensively investigated [91-114]. However, the early reports provided modest yields or mixtures of products and some involved use of solvents [94,96]. Clearly, there was still considerable scope for the development of superior methods that could be applicable on a commercial scale. Indeed, the commercial application of procedures involving zeolite-catalysed acylation of aromatic ethers [111,112] prompted us to report our own results in this area [115-117].

We showed that acetic anhydride is a much better reagent than either acetic acid or acetyl chloride for acetylation of anisole over zeolite catalysts, and that zeolite $\mathrm{H} \beta$ was the most active zeolite catalyst of those tried, followed by HY. Furthermore, using acetic anhydride over H $\beta$ ( 0.15 g per 5 mmol of anisole) in the absence of solvent at $120{ }^{\circ} \mathrm{C}$ for $2 \mathrm{~h}$ gave exclusively paramethoxyacetophenone (Scheme 9; $\mathrm{R}=\mathrm{R}^{\prime}=\mathrm{Me}$ ) in 98\% yield [115].

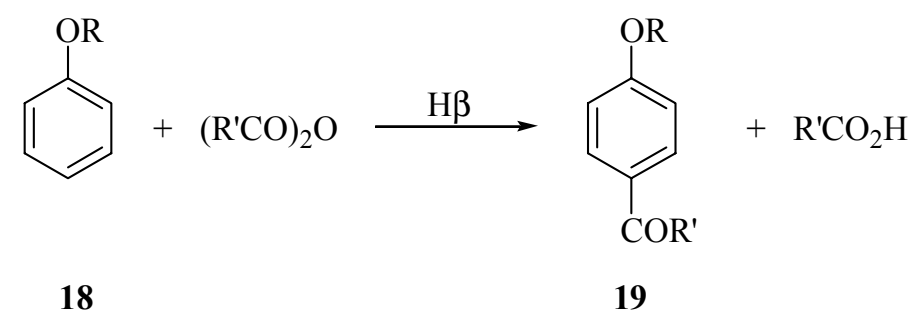

Scheme 9.

It was of interest to see if the reaction was general. Therefore, the reactions of anisole, phenetole and diphenyl ether with various carboxylic acid anhydrides (Scheme 9) were conducted under standard conditions $\left(100{ }^{\circ} \mathrm{C}, 3 \mathrm{~h}, 0.15 \mathrm{~g}\right.$ zeolite $\mathrm{H} \beta$ per $10 \mathrm{mmol}$ of substrate and anhydride). The yields of the para-acetylated products $\mathbf{1 9}$ obtained are recorded in Table $\mathbf{1 2}$. 
Table 12. Acylation of Aromatic Ethers (18) According to Scheme $9^{a}$

\begin{tabular}{|l|l|l|l|}
\hline Acylating agent & R & $\mathbf{R}^{\prime}$ & Yield of 19 (\%) \\
\hline \hline $\mathrm{Ac}_{2} \mathrm{O}$ & $\mathrm{Me}$ & $\mathrm{Me}$ & 76 \\
\hline$(\mathrm{EtCO})_{2} \mathrm{O}$ & $\mathrm{Me}$ & $\mathrm{Et}$ & 73 \\
\hline$\left(\mathrm{Pr}^{i} \mathrm{CO}\right)_{2} \mathrm{O}$ & $\mathrm{Me}$ & $\mathrm{Pr}^{i}$ & 73 \\
\hline$\left(\mathrm{Bu}{ }^{t} \mathrm{CO}\right)_{2} \mathrm{O}$ & $\mathrm{Me}$ & $\mathrm{Bu}^{t}$ & 10 \\
\hline $\mathrm{Ac} \mathrm{O}$ & $\mathrm{Et}$ & $\mathrm{Me}$ & 77 \\
\hline$(\mathrm{EtCO})_{2} \mathrm{O}$ & $\mathrm{Et}$ & $\mathrm{Et}$ & 74 \\
\hline$\left(\mathrm{Pr}^{i} \mathrm{CO}\right)_{2} \mathrm{O}$ & $\mathrm{Et}$ & $\mathrm{Pr}^{i}$ & 75 \\
\hline$\left(\mathrm{Bu}^{t} \mathrm{CO}\right)_{2} \mathrm{O}$ & $\mathrm{Et}$ & $\mathrm{Bu}^{t}$ & 14 \\
\hline $\mathrm{Ac}_{2} \mathrm{O}$ & $\mathrm{Mh}$ & $\mathrm{Me}$ & 52 \\
\hline$(\mathrm{EtCO})_{2} \mathrm{O}$ & $\mathrm{Ph}$ & $\mathrm{Et}^{i}$ & 43 \\
\hline$\left(\mathrm{Pr}^{i} \mathrm{CO}\right)_{2} \mathrm{O}$ & $\mathrm{Ph}$ & $\mathrm{Pr}^{i}$ & 27 \\
\hline$\left(\mathrm{Bu}{ }^{t} \mathrm{CO}\right)_{2} \mathrm{O}$ & $\mathrm{Ph}$ & $\mathrm{Bu}^{t}$ & 0 \\
\hline
\end{tabular}

${ }^{\mathrm{a}} \mathrm{H} \beta(1.5-2.5 \mathrm{~g})$, acylating agent $(30-50 \mathrm{mmol})$ and $\mathbf{1 8}(30-50 \mathrm{mmol})$ at $100^{\circ} \mathrm{C}$ for $3 \mathrm{~h} \mathrm{[115].}$

There was a general reduction in yield on going from acetic anhydride to the successively more hindered propionic, isobutyric and pivalic anhydrides, and also with increasing complexity of the ether. Consequently, the acylation of diphenyl ether with pivalic anhydride did not take place at all under the standard reaction conditions tried, presumably due to a combination of steric and electronic effects [115]. No attempt was made to optimise individual reactions, but it is likely that higher yields in reactions of diphenyl ether or using pivalic anhydride could be obtained by using more forcing conditions.

In order to investigate further the scope of acylation with a hindered acylating reagent, we studied the 2-phenylbutanoylation of anisole over zeolite $\mathrm{H} \beta$ [Scheme 9; $\left.\mathrm{R}=\mathrm{Me} ; \mathrm{R}^{\prime}=\mathrm{EtCH}(\mathrm{Ph})\right]$ or HY. We showed that 2-phenylbutanoyl trifluoroacetate, formed in situ from 2-phenylbutanoic acid and trifluoroacetic anhydride, was a more effective reagent than the simple anhydride, giving a $96 \%$ yield of $19\left[\mathrm{R}=\mathrm{Me}, \mathrm{R}^{\prime}=\mathrm{EtCH}(\mathrm{Ph})\right]$ after $4 \mathrm{~h}$ at reflux over $\mathrm{H} \beta[116]$.

The scope of the acylation reaction has also been extended to the acetylation of disubstituted benzenes. Reaction of $\mathbf{2 0}$ with acetic anhydride at $120{ }^{\circ} \mathrm{C}$ over $\mathrm{H} \beta$ or $\mathrm{HY}$ led to mixtures of regioisomers 21 and 22 (Scheme 10) [117]. The para-acetylated product 21 was obtained in a typical yield of $60-70 \%$, whereas the ortho-acetylated product 22 was never formed in greater than $25 \%$ yield.<smiles>CCOCCN</smiles>

20<smiles>COc1ccc(C(C)(C)C)c(C)c1</smiles>

21<smiles>COc1cc(C)ccc1C(C)(C)C</smiles>

22

Scheme 10. 
By contrast, acetylation of 2-substituted aryl ethers $\mathbf{2 3}$ with acetic anhydride over the large pore zeolites $\mathrm{H} \beta$ and $\mathrm{HY}$, in the absence of solvent, gave the corresponding para-acetylated products 24 (Scheme 11), generally in high yield (74-94\%) and selectivity [117].<smiles>[R]Oc1ccc([Y6])cc1[R]</smiles>

\section{Scheme 11.}

Similarly, regioselective acylation of 2,3-dihydrobenzofuran (DHBF, 25) gave the 5-acylated products 26 (Scheme 12) as pure compounds, uncontaminated by their isomeric products (Table 13) $[116,117]$.<smiles>c1ccc2c(c1)CCO2</smiles><smiles>O=C([18O])O[Na]</smiles>

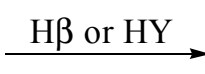
25<smiles>[R]C(=O)c1ccc2c(c1)CCO2</smiles>

26

Scheme 12.

Table 13. Acylation of 2,3-Dihydrobenzofuran (25) According to Scheme $12^{a}$

\begin{tabular}{|l|l|l|l|}
\hline Zeolite & R & t (h) & Yield of 23 (\%) \\
\hline $\mathrm{H} \beta$ & $\mathrm{Me}$ & 1.5 & 95 \\
\hline $\mathrm{H} \beta$ & $\mathrm{Et}$ & 1.5 & 90 \\
\hline $\mathrm{H} \beta$ & $\mathrm{Pr}^{i}$ & 1.5 & 70 \\
\hline $\mathrm{H} \beta$ & $\mathrm{Bu}^{t}$ & 4.5 & 29 \\
\hline $\mathrm{HY}$ & $\mathrm{Bu}^{t}$ & 4.5 & 57 \\
\hline $\mathrm{H} \beta$ & $\mathrm{Ph}$ & 1.5 & 26 \\
\hline $\mathrm{H} \beta$ & $\mathrm{Ph}$ & 4.5 & 29 \\
\hline $\mathrm{HY}$ & $\mathrm{Ph}$ & 4.5 & 40 \\
\hline $\mathrm{H} \beta$ & $\mathrm{ClCH}$ & 1.5 & 8 \\
\hline
\end{tabular}

${ }^{\mathrm{a}}$ Catalyst $(0.5 \mathrm{~g}),(\mathrm{RCO})_{2} \mathrm{O}(12 \mathrm{mmol})$ and $\mathbf{2 5}(10 \mathrm{mmol})$ at $120{ }^{\circ} \mathrm{C}$ for the indicated reaction time [116,117].

The results indicated that $\mathrm{H} \beta$ was not as effective as a catalyst for reactions involving more hindered anhydrides (95 and 90\% yield after $1.5 \mathrm{~h}$ when $\mathrm{R}=\mathrm{Me}$ and Et, compared to $29 \%$ after $4.5 \mathrm{~h}$ 
when $\mathrm{R}=\mathrm{Ph}$ or $\mathrm{Bu}^{t}$ ) [116,117]. However, $\mathrm{HY}$ showed a modest improvement (40 and 57\%, respectively for $\mathrm{R}=\mathrm{Ph}$ and $\mathrm{Bu}^{t}$ after $4.5 \mathrm{~h}$ ) [116].

A particularly interesting example was regioselective acylation of 25 using ethyl oxalyl chloride as acylating agent to produce ethyl (2,3-dihydrobenzofuran-5-yl)glyoxylate (27), which is a useful pharmaceutical intermediate (Scheme 13). The Friedel-Crafts acylation of $\mathbf{2 5}$ with ethyl oxalyl chloride in the presence of $\mathrm{AlCl}_{3}$ gave the desired product 27 in $88 \%$ yield. The aim of this work, therefore, was to use a zeolite catalyst to replace the $\mathrm{AlCl}_{3}$.<smiles>CCOC(=O)C(=O)Cl</smiles>

25<smiles>CCOC(=O)C(=O)c1ccc2c(c1)CCO2</smiles>

27

Scheme 13.

Initially, a range of various zeolites was tested. No reaction took place at room temperature with any zeolite tried. At higher temperatures $\left(50-100{ }^{\circ} \mathrm{C}\right)$ a trace of the desired product 27 was detected in reactions catalysed by HY, while the use of $\mathrm{H} \beta$ gave it in better but still very low yield, which increased with reaction temperature [116]. Therefore, the effect of solvent at different reaction times and temperatures over $\mathrm{H} \beta$ was studied.

The yield of $\mathbf{2 7}$ increased to $c a$. $20 \%$ when reactions were carried out in chlorinated solvents under reflux conditions for prolonged periods over $\mathrm{H} \beta(0.5 \mathrm{~g}$ per $10 \mathrm{mmol}$ of $\mathbf{2 5})$. The yield improved to $38 \%$ when the quantity of zeolite $\mathrm{H} \beta$ was increased (to $2.0 \mathrm{~g}$ per $10 \mathrm{mmol}$ of 25) [116]. An even better yield (51\%) was achieved by carrying out the reaction under reflux conditions for $168 \mathrm{~h}$ in chloroform $(10 \mathrm{ml})$ over $\mathrm{H} \beta(2.0 \mathrm{~g})$. However, when the reaction was carried out in a high boiling solvent (e.g. chlorobenzene) for a prolonged period of time, the yield was low even though the amount of residual starting material $\mathbf{2 5}$ was also low. Initially, it was not clear what had happened to the rest of the starting material.

The reaction mixture was therefore worked up and purified by kugelrohr distillation to remove the unreacted starting material 25. The crude distillation residue then was purified by flash column chromatography to give three isolated by-products, identified as compounds 28-30. The formation of compound $\mathbf{2 8}$ appeared to involve attack of a further molecule of $\mathbf{2 5}$ on the ketone carbonyl group of $\mathbf{2 7}$ 
to give compound 31, followed by reduction. However, the mechanism of the reduction step remains unknown. Intermediate $\mathbf{3 1}$ could also be the precursor for compound $\mathbf{3 0}$. It is also conceivable that compound $\mathbf{3 1}$ could be formed via a benzilic acid type rearrangement from compound $\mathbf{2 9}$, followed by transesterification.

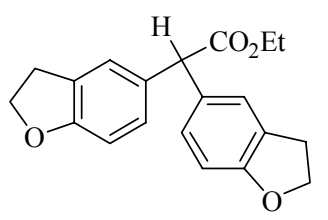

28

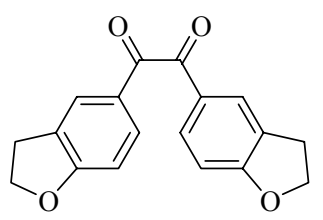

29

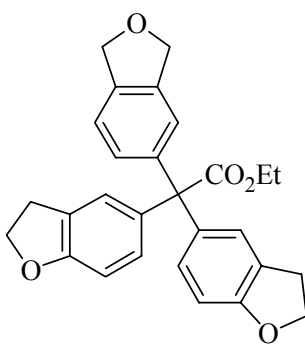

30

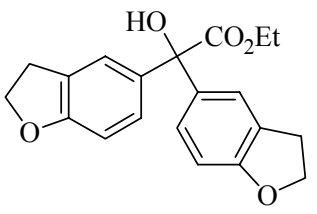

31

Since the processes involved in formation of the by-products 28-30 involve reaction of $\mathbf{2 7}$ with the excess of $\mathbf{2 5}$, the key to preventing formation of such by-products would be to avoid having excess of $\mathbf{2 5}$. Indeed, the addition of $\mathbf{2 5}$ over a longer period of time leads to a significant improvement in the yield of $\mathbf{2 7}$ and in the total mass balance accounted for. A high yield of $\mathbf{2 7}(73 \%)$ could be obtained by conducting the reaction in ethyl oxalyl chloride $(30 \mathrm{ml})$ as solvent at a high temperature for a prolonged period $(168 \mathrm{~h})$ in the presence of a large quantity of $\mathrm{H} \beta(5.0 \mathrm{~g})$. Unfortunately, these conditions are not attractive for commercial application.

\section{REGIOSELECTIVE METHANESULFONYLATION OF AROMATIC COMPOUNDS}

Direct sulfonylation of aromatic compounds is one of the most important methods for the synthesis of sulfones $[118,119]$. However, relatively little detailed attention has been paid to this reaction [120-124]. In order to allow the reaction to proceed at a satisfactory rate, an activator such as $\mathrm{AlCl}_{3}$ is usually needed, but $\mathrm{AlCl}_{3}$ forms a 1:1 complex with the product and therefore has to be used in more than stoichiometric amount [118]. Recently, several new catalytic systems have been developed for such sulfonylation reactions. These systems include use of cation-exchanged zeolites (ZSM-5, Y, ß) [125], $\mathrm{Fe}(\mathrm{III})$-exchanged montmorillonite clay [126,127], Bi(III) triflate [128], triflic acid (TfOH)$\mathrm{Bi}(\mathrm{III})$ halide [129] and microwave irradiation in the presence of a small quantity of certain metal salts [130-132]. 
Methanesulfonylation of toluene with $\mathrm{AlCl}_{3}$ as the catalyst and methanesulfonyl chloride as reagent affords methyl tolyl sulfones in only $52 \%$ yield with an ortho/meta/para isomer distribution of 53/14/33 [121]. Furthermore, the $\mathrm{AlCl}_{3}$ cannot be recovered and creates an effluent problem. At the time we started to investigate methanesulfonylation, the best para-selectivity, reported in the patent literature, was obtained by the use of zeolite $\mathrm{H} \beta$ as catalyst with methanesulfonyl chloride as reagent, which in the most favourable cases gave methyl tolyl sulfones in a yield of $14 \%$, of which $81 \%$ was the para-isomer [122]. Therefore, we undertook a detailed study of methanesulfonylation of simple aromatic compounds in the hope of finding a better catalyst/reagent system.

Initially, different methanesulfonylating agents were tested for efficacy in methanesulfonylation of toluene (1), under reflux conditions in the presence of selected zeolite catalysts. Methanesulfonic anhydride gave much better yields than methanesulfonyl chloride in these tests, while other reagents (acid, amide and ester) produced negligible yields of methanesulfonylated products. Methanesulfonic anhydride was therefore chosen for further studies in the presence of a range of zeolite catalysts. Under reflux conditions, the products of methanesulfonylation of 1 were methyl $o$-tolyl sulfone (32), methyl $m$-tolyl sulfone (33) and methyl $p$-tolyl sulfone (34) (Scheme 14). The yields and selectivities obtained under a standard set of conditions are recorded in Table 14 $[133,134]$.

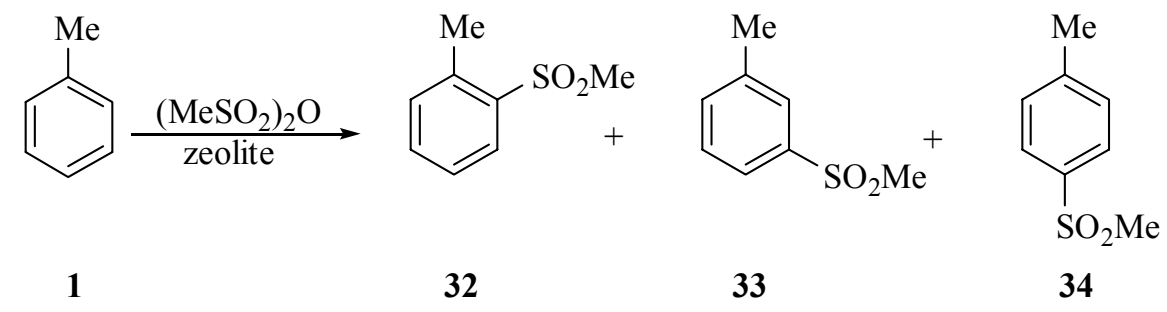

Scheme 14.

The results indicated that H-Mordenite and HZSM-5 are not good catalysts for the methanesulfonylation of toluene (1). The poor yields (9-22\%) obtained on use of H-Mordenite may be due to the limited one-dimensional entry to the pores of this solid, which causes statistical disadvantage in comparison to a catalyst with two or three-dimensional entry. In the HZSM-5 case, reaction within the restricted pores of the catalyst is highly unlikely, so that any reaction that took place was probably catalysed at external sites [134]. 
Table 14. Methanesulfonylation of Toluene (1) Over Various Zeolites According to Scheme 14

\begin{tabular}{|c|c|c|c|c|}
\hline \multirow[t]{2}{*}{ Zeolite (Si/AI) } & \multirow[t]{2}{*}{ Yield (\%) } & \multicolumn{3}{|c|}{ Isomers proportions (\%) } \\
\hline & & 32 & 33 & 34 \\
\hline $\mathrm{H} \beta(25)$ & 78 & 32 & 11 & $\overline{57}$ \\
\hline HY (2.7) & 6 & 44 & 10 & 46 \\
\hline HY (2.75) & 11 & 41 & 9 & 50 \\
\hline HY (5.25) & 34 & 44 & 10 & 46 \\
\hline HY (16.15) & 59 & 47 & 13 & 40 \\
\hline HY (19.4) & 56 & 46 & 14 & 40 \\
\hline HY (30.15) & 50 & 47 & 12 & 41 \\
\hline HY (45) & 12 & 46 & 12 & 42 \\
\hline $\mathrm{HX}(1.2)$ & 0 & - & - & - \\
\hline $\mathrm{Na} \beta(25)$ & 12 & 10 & 5 & 85 \\
\hline $\mathrm{NaY}(12.5)$ & 56 & 47 & 8 & 45 \\
\hline $\mathrm{NaY}(28)$ & 62 & 48 & 8 & 44 \\
\hline H-Mordenite (10) & 9 & 43 & 12 & 45 \\
\hline H-Mordenite (18.23) & 22 & 47 & 14 & 39 \\
\hline HZSM-5 (38) & 36 & 48 & 15 & 37 \\
\hline HZSM-5 (150) & 6 & 48 & 14 & 38 \\
\hline
\end{tabular}

${ }^{\mathrm{a}}$ Zeolite $(0.6 \mathrm{~g}),\left(\mathrm{MeSO}_{2}\right)_{2} \mathrm{O}(1.22 \mathrm{~g}, 7 \mathrm{mmol})$ and dry toluene $(15 \mathrm{ml})$ under reflux for $18 \mathrm{~h}[133,134]$.

In addition, we found that zeolite $\mathrm{HX}$ gave no reaction, presumably because its acidic sites are not strong enough. A moderate yield (34-59\%) of sulfones 32-34 could be achieved with some HY zeolite samples. Zeolite $\mathrm{H} \beta$ was the most active zeolite tried, giving a 78\% yield of sulfones $\mathbf{3 2 - 3 4}$ with an isomer distribution of $32 / 11 / 57$. It was found that partially exchanged zeolite Naß produced only a low yield (12\%) of methanesulfonylated products 32-34, but with high para-selectivity $(\mathbf{3 2} / \mathbf{3 3} / \mathbf{3 4}=10 / 5 / 85)$. Therefore, a series of experiments was conducted to determine the effect on yield and selectivity over various quantities of completely exchanged zeolite $\mathrm{Na} \beta$ using various modes of zeolite addition [134].

It was found that the use of fully exchanged $\mathrm{Na} \beta(0.6 \mathrm{~g})$ gave an overall yield of only $6 \%$ of sulfones 32-34, of which 94\% was the para-isomer 34. Increasing the amount of catalyst to $1 \mathrm{~g}$ improved the yield to $18 \%$, of which $95 \%$ was isomer 34. When the amount of catalyst was increased to $2 \mathrm{~g}$, however, the yield was reduced to $11 \%$, with para-selectivity of $92 \%$. A very high paraselectivity $(\mathbf{3 2} / \mathbf{3 3} / \mathbf{3 4}=2 / 1 / 97)$ could be achieved, but in only $15 \%$ yield, when an extra three additional portions of fresh $\mathrm{Na} \beta(0.5 \mathrm{~g}$ each $)$ were added into the reaction mixture at $4 \mathrm{~h}$ intervals. Other variations in the mode of catalyst addition did not improve either the yield or selectivity. Therefore, this seems to be the limit to the yield, but these reactions are nevertheless highly para-selective. 
In view of the high para-selectivity achieved with zeolite $\mathrm{Na} \beta$, various cation-exchanged forms of zeolite $\beta$ were tested as catalysts in methanesulfonylation of toluene (1) under a standard set of conditions (Scheme 14). A selection of the results is reported in Table 15 [133,134].

Table 15. Methanesulfonylation of Toluene (1) Over Various Cation-Exchanged Zeolites of Type $\beta$ According to Scheme $14^{\mathrm{a}}$

\begin{tabular}{|l|l|l|}
\hline Zeolite & Overall Yield (\%) of 32-34 & Proportion (\%) of 34 \\
\hline \hline $\mathrm{H} \beta$ & 78 & 57 \\
\hline $\mathrm{HY}$ & 11 & 50 \\
\hline $\mathrm{Li}^{+} \beta$ & 51 & 55 \\
\hline $\mathrm{Na}^{+} \beta$ & 18 & 95 \\
\hline $\mathrm{K}^{+} \beta$ & 12 & 53 \\
\hline $\mathrm{Rb}^{+} \beta$ & 3 & 79 \\
\hline $\mathrm{Cs}^{+} \beta$ & 1 & 67 \\
\hline $\mathrm{Be}^{2+} \beta$ & 52 & 67 \\
\hline $\mathrm{Mg}^{2+} \beta$ & 69 & 43 \\
\hline $\mathrm{Ca}^{2+} \beta$ & 62 & 61 \\
\hline $\mathrm{Sr}^{2+} \beta$ & 33 & 62 \\
\hline $\mathrm{Ba}^{2+} \beta$ & 50 & 71 \\
\hline $\mathrm{Ce}^{3+} \beta$ & 68 & 50 \\
\hline $\mathrm{Cr}^{3+} \beta$ & 73 & 50 \\
\hline $\mathrm{Fe}^{3+} \beta$ & 46 & 54 \\
\hline $\mathrm{Co}^{2+} \beta$ & 77 & 55 \\
\hline $\mathrm{Cu}^{2+} \beta$ & 65 & 55 \\
\hline $\mathrm{Hg}^{2+} \beta$ & 28 & 77 \\
\hline
\end{tabular}

${ }^{\mathrm{a}}$ Zeolite $(1 \mathrm{~g}),\left(\mathrm{MeSO}_{2}\right)_{2} \mathrm{O}(1.22 \mathrm{~g}, 7 \mathrm{mmol})$ and dry toluene $(15 \mathrm{ml})$ under reflux for $18 \mathrm{~h}[133,134]$.

Several features of interest emerge from the results recorded in Table 15. Within Group 1 the yields decrease down the group as the cations become larger. The larger cations presumably block entry to the pore system of the zeolite, spoiling its potential as a catalyst. However, the restriction of the pore size might also be expected to lead to an increase in para-selectivity, which is apparent with sodium but tails off thereafter. With the larger cations it may be that a substantial proportion of the product arises from reaction at the external surface, thereby reducing the regioselectivity and also limiting the yield because of the relatively small number of available sites $[133,134]$.

For Group 2 the yields are generally higher than their Group 1 counterparts. Presumably the smaller divalent cations allow easier entry into the pore network, which would be consistent with the increased yields. There is also a general increase in para-selectivity going down the group as the cations get larger, but again at the expense of overall yield. $\mathrm{Be}^{2+} \beta$ appears to be an exception, giving a lower yield and higher selectivity than its $\mathrm{Mg}^{2+} \beta$ analogue $[133,134]$. 
Most trivalent cations, as well as divalent cations of the first transition series, produced reasonable yields (typically $60-70 \%$ ) and para-product proportions in the range of $40-50 \%$. This is consistent with the idea that small cations allow more space for reaction and it is clear that overall there is a broad correlation between cation size and both yield and selectivity. Unfortunately, there is a trade-off between the two, with those cases providing highest para-selectivity also giving rather poor yields $[133,134]$.

In order to explore the scope of the reaction, similar conditions were applied to a range of mono-substituted benzenes 5 over $\mathrm{H} \beta$ or $\mathrm{Na} \beta$ zeolite (Scheme 15). The yields of the corresponding methanesulfonylated products $\mathbf{3 5 - 3 7}$ and the selectivity are recorded in Table $\mathbf{1 6}$ [134].

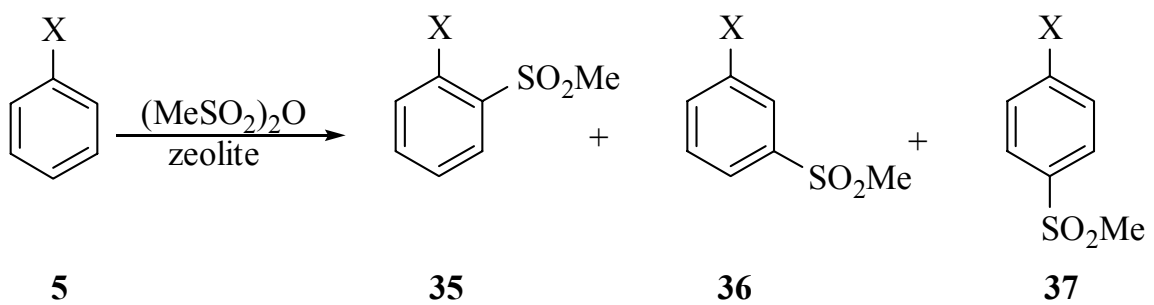

Scheme 15.

Table 16. Methanesulfonylation of Aromatic Compounds 5 According to Scheme $15^{\text {a }}$

\begin{tabular}{|l|l|l|l|l|l|}
\hline Zeolite & X & Yield (\%) & \multicolumn{3}{|l|}{ Isomers proportions (\%) } \\
\cline { 4 - 6 } & & & $\mathbf{3 5}$ & $\mathbf{3 6}$ & $\mathbf{3 7}$ \\
\hline $\mathrm{H} \beta$ & $\mathrm{Me}$ & 78 & 32 & 11 & 57 \\
\hline $\mathrm{Na} \beta$ & $\mathrm{Me}$ & 18 & 3 & 2 & 95 \\
\hline $\mathrm{H} \beta$ & $\mathrm{Et}$ & 53 & 15 & 11 & 74 \\
\hline $\mathrm{Na} \beta$ & $\mathrm{Et}$ & 13 & 14 & 10 & 76 \\
\hline $\mathrm{H} \beta$ & $\mathrm{P}^{i}$ & 74 & 13 & 20 & 67 \\
\hline $\mathrm{Na} \beta$ & $\mathrm{Pr}^{i}$ & 5 & 2 & 8 & 90 \\
\hline $\mathrm{H} \beta$ & $\mathrm{Ph}$ & 66 & - & - & 100 \\
\hline $\mathrm{Na} \beta$ & $\mathrm{Ph}$ & 2 & - & - & 100 \\
\hline $\mathrm{H} \beta$ & $\mathrm{OMe}$ & 54 & 26 & - & 74 \\
\hline $\mathrm{Na} \beta$ & $\mathrm{OMe}$ & 43 & 17 & - & 83 \\
\hline $\mathrm{H} \beta$ & $\mathrm{F}$ & 12 & 4 & 11 & 85 \\
\hline $\mathrm{Na} \beta$ & $\mathrm{F}$ & 2 & - & - & 100 \\
\hline $\mathrm{H} \beta$ & $\mathrm{Cl}$ & 23 & - & 12 & 88 \\
\hline $\mathrm{H} \beta$ & $\mathrm{Br}$ & 33 & - & - & 100 \\
\hline
\end{tabular}

${ }^{\mathrm{a}} \mathrm{H} \beta(0.6 \mathrm{~g})$ or $\mathrm{Na} \beta(1 \mathrm{~g}),\left(\mathrm{MeSO}_{2}\right)_{2} \mathrm{O}(7 \mathrm{mmol})$ and $\mathbf{5}(15 \mathrm{ml})$ under reflux for $18 \mathrm{~h}[134]$.

The results indicated that in all cases the proton-exchanged zeolite $\beta$ was considerably more active than $\mathrm{Na} \beta$. Anisole was the only substrate that afforded a reasonable yield $(43 \%)$ of the corresponding sulfones when $\mathrm{Na} \beta$ was used as a catalyst. The high reactivity of anisole to electrophilic 
substitution may be the reason for the relatively high yield over $\mathrm{Na} \beta$. Also, substitution of anisole generally favours higher para-selectivity [134]. The procedure using $\mathrm{H} \beta$ has also been applied successfully to methanesulfonylation reactions of some disubstituted benzene derivatives [134].

\section{REGIOSELECTIVE HALOGENATION OF AROMATIC COMPOUNDS}

The usual methods for halogenation of aromatics lead in many cases to mixtures of regioisomers that may be difficult to separate. Commercial processes might be simplified considerably by the use of solid, heterogeneous catalysts such as zeolites, since separation of the catalyst from the reaction mixture would be easy [135]. In initiating a study of zeolites as catalysts for such reactions, we also hoped to achieve improvements in regioselectivity.

\subsection{Selective Chlorination of Aromatic Compounds}

Numerous reagents have been used to enhance either the ortho or para selectivity of aromatic chlorination reactions [136-158]. The rates of chlorination reactions with molecular chlorine [147,148] are generally faster than those with sulfuryl chloride $[142,145]$. However, sulfuryl chloride is a slightly more para-selective reagent than chlorine. Unfortunately, selectivity in the reaction of simple substrates like toluene remains a problem. Therefore, we investigated the chlorination of toluene over various zeolite catalysts.

We showed that tert-butyl hypochlorite is a much better reagent than sulfuryl chloride for chlorination of toluene over zeolite catalysts, and that partially proton-exchanged faujasite $\mathrm{X}(\mathrm{HNaX})$ was the most selective zeolite catalyst tried. Furthermore, using tert-butyl hypochlorite over HX produced almost quantitative ring chlorination of toluene within one hour at $25{ }^{\circ} \mathrm{C}$ in tetrachloromethane as solvent (Scheme 16, $\mathrm{X}=\mathrm{Me}$ ) [159].<smiles>[X]c1ccc(Cl)cc1</smiles>

Scheme 16. 
The fact that the reaction proceeded readily with zeolite HX as catalyst is consistent with the fact that faujasite has the largest pore diameter of all the zeolites tried and also has a three dimensional lattice structure with many interconnecting cavities of even greater dimensions, so that diffusion of substrate and reagents through the pores is relatively easy. Although zeolite HY also has the faujasite structure, it is more strongly acidic than HX and this resulted in a greater proportion of by-products. Therefore, use of HX was preferable.

Since the HX zeolite proved to be such a useful catalyst, the chlorination of toluene over HX was studied further. The effect of different solvents on yield and selectivity was investigated. Some of the results obtained are recorded in Table 17.

Table 17. Chlorination of Toluene According to Scheme $16(\mathrm{X}=\mathrm{Me})^{\mathrm{a}}$

\begin{tabular}{|l|l|l|l|l|}
\hline \multirow{2}{*}{ Solvent } & \multirow{2}{*}{$\mathbf{( h )}$} & Yield (\%) & \multicolumn{2}{|l|}{ Isomer proportions (\%) } \\
\cline { 4 - 5 } & & & ortho & para \\
\hline \hline Pentane & 1 & 78 & 37 & 63 \\
\hline Toluene & 28 & - & 29 & 71 \\
\hline $\mathrm{CH}_{2} \mathrm{Cl}_{2}$ & 1 & 95 & 26 & 74 \\
\hline $\mathrm{CCl}_{4}$ & 1 & 95 & 26 & 74 \\
\hline $\mathrm{Et}_{2} \mathrm{O}$ & 0.5 & 63 & 8 & 92 \\
\hline $\mathrm{CH}_{2} \mathrm{Cl}_{2}: \mathrm{Et}_{2} \mathrm{O}(3: 1)$ & 1 & 95 & 9 & 91 \\
\hline $\mathrm{DMF}$ & 24 & 5 & 50 & 50 \\
\hline $\mathrm{MeCN}$ & 0.5 & 100 & 18 & 82 \\
\hline $\mathrm{MeOH}$ & 20 & 46 & 60 & 40 \\
\hline
\end{tabular}

${ }^{\mathrm{a}}$ Toluene $(2.5 \mathrm{mmol}), \mathrm{Bu}{ }^{t} \mathrm{OCl}(2.5 \mathrm{mmol}), \mathrm{HNaX}(1.5 \mathrm{~g})$ and solvent $(10 \mathrm{ml})$ at $25^{\circ} \mathrm{C}$ for the reaction time [159].

Good yields of monochlorotoluenes were obtained both in a non-polar solvent such as pentane and in a very polar aprotic solvent like acetonitrile. Solvents having a strongly coordinating functionality (e.g. DMF) tended to deactivate the acid sites of the zeolite and so to inhibit the reaction completely. The slow reaction rate observed in methanol may reflect the fact that methanol is also capable of forming strong hydrogen bonds with the acid sites of the faujasite pores, diminishing the activity and also inhibiting diffusion of reactants in and out of the lattice. The high regioselectivity ( $92 \%$ para) obtained in diethyl ether probably depends on the geometrical flexibility and electron density distribution of diethyl ether, which may render it capable within the pores of stabilising the tert-butyl hypochlorite oxonium cation that is likely to be involved in the reaction mechanism. Unfortunately, in the case of less active substrates, for which the rates of reaction were slower, the competing reaction of tert-butyl hypochlorite with ether itself became a problem. In view of this, 
acetonitrile appeared to be a better solvent for development of a general procedure. Use of this solvent gave a quantitative yield of chlorinated toluenes with para/ortho product distribution of 82/18 [159].

$\mathrm{The} \mathrm{Bu}^{t} \mathrm{OCl} / \mathrm{HNaX} / \mathrm{MeCN}$ system has also been applied successfully to a range of substituted aromatics of moderate activity, ranging from about anisole at the most active to halobenzenes at the less active limits (Scheme 16). Some of the results obtained are recorded in Table $\mathbf{1 8 .}$

Table 18. Chlorination of Aromatic Compounds 5 According to Scheme $16^{\text {a }}$

\begin{tabular}{|l|l|l|l|l|l|}
\hline $\mathbf{X}$ & $\mathbf{T}\left({ }^{\circ} \mathbf{C}\right)$ & $\mathbf{t}(\mathbf{h})$ & Yield (\%) & \multicolumn{2}{|l|}{ Isomer proportions (\%) } \\
\cline { 5 - 6 } & & & & $\mathbf{3 8}$ & $\mathbf{3 9}$ \\
\hline \hline $\mathrm{OMe}$ & 25 & 3 & 100 & 18 & 82 \\
\hline $\mathrm{Me}$ & 25 & 1 & 100 & 18 & 82 \\
\hline $\mathrm{Et}$ & 40 & 3.5 & 100 & 10 & 90 \\
\hline $\mathrm{Pr}^{i}$ & 40 & 96 & 90 & 20 & 80 \\
\hline $\mathrm{Bu}^{t}$ & 40 & 96 & 99 & 2 & 98 \\
\hline $\mathrm{Ph}$ & 45 & 72 & 86 & 14 & 86 \\
\hline $\mathrm{Cl}$ & 40 & 120 & 95 & 3 & 97 \\
\hline $\mathrm{Br}$ & 40 & 96 & 75 & 3 & 97 \\
\hline
\end{tabular}

${ }^{\mathrm{a}} 5(2.5 \mathrm{mmol}), \mathrm{Bu}^{t} \mathrm{OCl}(2.5 \mathrm{mmol}), \mathrm{MeCN}(10 \mathrm{ml})$ and zeolite $\mathrm{HX}(1.5 \mathrm{~g})$ at the indicated temperature and reaction time [159].

Excellent yields (75-100\%) and high para-selectivities (82-97\%) were achieved although the reactions with less active substrates were rather slow. Furthermore, the reaction was shown to work for the preparation of para-chlorotoluene and para-dichlorobenzene on 0.1 mole scale without any detrimental effects on either the yield or the selectivity [159].

In view of the relative lack of success in chlorination of toluene over zeolites other than HX, even other large pore zeolites, it was likely that the transition state for the reaction was taking up most of the space within the cavity of the HX zeolite. Indeed, it was likely that the geometrical constraints imposed as a result were in large part responsible for the impressive regioselectivity. Therefore, it was by no means certain that disubstituted benzenes would react at all readily with tert-butyl hypochlorite over zeolite HX. Nevertheless, the $\mathrm{Bu}^{t} \mathrm{OCl} / \mathrm{HNaX} / \mathrm{MeCN}$ system was applied to the selective chlorination of a range of disubstituted benzenes.

Most disubstituted aromatics tried could eventually be chlorinated in high yield with moderate to excellent selectivities. Slightly deactivated ortho- and meta-chlorotoluenes gave predominantly chlorination para to one of the substituents with a substantial preference for substitution para to chlorine. para-Chlorotoluene was very selectively chlorinated ortho to the methyl group but the very low rate of the reaction makes it impractical for synthetic purposes [159]. More activated ortho and 
meta-xylenes gave good para-selectivity $\left(\mathrm{ca} .90 \%\right.$ at $\left.20{ }^{\circ} \mathrm{C}\right)$, but heating the reaction mixture to $40{ }^{\circ} \mathrm{C}$ led to the emergence of unwanted polychlorinated compounds [159]. para-Xylene afforded $o$-chloro$p$-xylene together with polychlorinated aromatics at $40{ }^{\circ} \mathrm{C}$. ortho-Chloroanisole was very selectively (ca. $100 \%$ ) chlorinated para to the methoxy moiety and the zeolite provided a genuine catalytic effect on the reaction, as demonstrated when a control reaction was performed without the zeolite [159].

\subsection{Selective Bromination of Aromatic Compounds}

There have been a number of studies of solid catalysts in regioselective bromination of aromatic compounds [160-166]. However, in many cases limited improvement in selectivity was shown. Following our success in developing a para-selective chlorination reaction for aromatic substrates of moderate activity by use of tert-butyl hypochlorite [159], we attempted the analogous reaction of toluene (1) with tert-butyl hypobromite as brominating agent (Scheme 17). Several zeolites were tested and reactions were carried out at $20{ }^{\circ} \mathrm{C}$ for one hour in a mixture of tetrachloromethane and diethyl ether as solvent [167]. Some of the results obtained are recorded in Table 19.

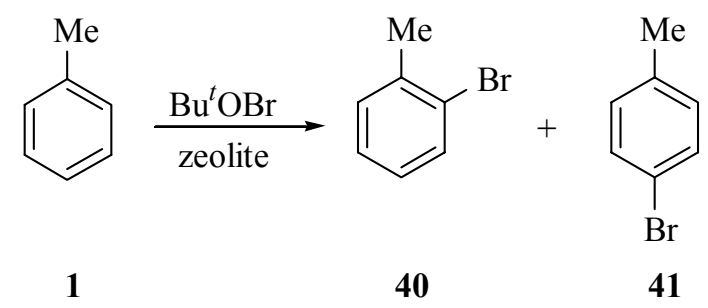

Scheme 17.

Table 19. Bromination of Toluene Over Various Zeolites According to Scheme $17^{\text {a }}$

\begin{tabular}{|l|l|l|l|}
\hline \multirow{2}{*}{ Zeolite } & \multirow{2}{*}{ Yield (\%) } & \multicolumn{2}{|l|}{ Proportion of isomers (\%) } \\
\cline { 3 - 4 } & & $\mathbf{4 0}$ & $\mathbf{4 1}$ \\
\hline \hline $\mathrm{HNaX}$ & 49 & - & 100 \\
\hline $\mathrm{HNaY}$ & 77 & 36 & 64 \\
\hline $\mathrm{H}-\mathrm{Mordenite}$ & 62 & 54 & 46 \\
\hline $\mathrm{HZSM}-5$ & 4 & 30 & 70 \\
\hline
\end{tabular}

${ }^{\mathrm{a}}$ Zeolite $(1.5 \mathrm{~g}), \mathrm{Bu}{ }^{t} \mathrm{OBr}(2.6 \mathrm{mmol}), \mathbf{1}(2.5 \mathrm{mmol}), \mathrm{Et}_{2} \mathrm{O}(7.5 \mathrm{ml})$ and $\mathrm{CCl}_{4}(2.5 \mathrm{ml})$ at $20^{\circ} \mathrm{C}$ for $1 \mathrm{~h} \mathrm{[167].}$

The results indicated that for the medium pore zeolite HZSM-5, the reaction was slow and the yield was very low (4\%), while the large pore zeolites H-mordenite and HY gave reasonable yields but in low para-selectivity. No other catalyst matched the para-selectivity of $\mathrm{HNaX}$, which has large pores 
to allow reasonable diffusion but weakly acidic sites. This appeared to favour a reaction that was sufficiently mild to allow the shape-selective constraints of the zeolite pores to exert maximum effect [167].

The low yield obtained over $\mathrm{HNaX}$ was probably because the rate of the reaction was slow enough to allow effective competition from destruction of the hypobromite in ether. The yield could be improved by use of a solvent mixture containing a lower proportion of ether, but at the expense of reduced selectivity. Furthermore, when the reaction over HX was tried with less active substrates, destruction of the hypobromite seemed to become the principle reaction, so that the yields of products were very low (0-36\%) [167]. Consequently, although somewhat better yields could probably be achieved by use of excess reagent, it seemed unlikely that the reaction would be useful as a general method. Therefore, our attention was next turned to use of bromine as the brominating reagent in the para-selective bromination reaction of simple aromatics $[167,168]$.

Early results from Sasson's group had indicated that significant improvements could be achieved in selective bromination of toluene (1) using bromine as the brominating agent, zeolite $\mathrm{Y}$ as catalyst and an epoxide as a hydrogen bromide scavenger. Although the selectivity and rate of reaction diminished as the reaction proceeded, these procedures gave excellent para-selectivity at low yield [169-172]. Therefore, we decided to investigate further the para-selective bromination of toluene (1) using bromine over various zeolites and in particular zeolite NaY (Scheme 18; $\mathrm{X}=\mathrm{Me}$ ) $[167,168]$.<smiles>[X]c1ccc(Br)cc1</smiles>

Scheme 18.

We introduced a modification of the procedure used by Sasson, using the NaY zeolite in larger quantity. For a room temperature reaction using bromine as brominating agent, a $98 \%$ yield of parabromotoluene with a paralortho ratio of around 100 was obtained [167,168]. This procedure represented the highest para-selectivity yet achieved in high yielding bromination reactions of toluene, and pure para-bromotoluene could be obtained by simple distillation. 
In order to explore the scope of the reaction, similar conditions were applied to a range of substituted benzenes 5 according to Scheme 18. The yields and selectivities of brominated products are recorded in Table $\mathbf{2 0}[167,168]$.

Table 20. Bromination of Simple Aromatic Compounds 5 According to Scheme $18^{a}$

\begin{tabular}{|l|l|l|l|}
\hline \multirow{2}{*}{$\mathbf{X}$} & \multicolumn{2}{|l|}{ Yield (\%) } & $\mathbf{4 2}$ \\
\cline { 2 - 4 } & $\mathbf{5}$ & 1 & $\mathbf{4 3}$ \\
\hline \hline $\mathrm{Me}$ & - & 1 & 98 \\
\hline $\mathrm{Et}$ & - & - & 97 \\
\hline $\mathrm{Pr}^{i}$ & - & - & 98 \\
\hline $\mathrm{Bu}^{t}$ & 2 & - & 97 \\
\hline $\mathrm{F}$ & $8(6)^{\mathrm{b}}$ & - & $92(93)^{\mathrm{b}}$ \\
\hline $\mathrm{Cl}$ & $22(17)^{\mathrm{b}}$ & - & $78(82)^{\mathrm{b}}$ \\
\hline $\mathrm{Br}$ & $44(34)^{\mathrm{b}}$ & $56(66)^{\mathrm{b}}$ \\
\hline $\mathrm{OMe}$ & - & - & 93 \\
\hline
\end{tabular}

The results in Table $\mathbf{2 0}$ indicated that the reaction gave high yields and para-selectivities for a range of substituted benzenes 5 of moderate activity, including alkyl and halogenobenzenes [167,168]. The selectivity was remarkable, almost exclusive formation of the para-isomer being achieved in all cases. In the many prior studies of zeolite-induced aromatic bromination reactions [160,169-172] selectivities at total conversion were significantly less, especially for toluene. Also, conventional wisdom would maintain that space within the pores of zeolite $\mathrm{Y}$ was so abundant that there was little opportunity for significant shape-selectivity. It appeared to be important that the reaction required the substrate, the bromine and $\mathrm{NaY}$ all to be involved in the process. Perhaps even the presence of solvent molecules plays a role. In this case, the space within the pores could become much more congested than might be envisaged on cursory consideration, and this might lead to the observed selectivity.

\section{REARRANGEMENT OF AROMATIC EPOXIDES}

Aryl-substituted epoxides are versatile compounds for aromatic syntheses due to their ready availability and easy transformation to a wide range of organic compounds [173-176]. Several catalytic systems have been developed for the rearrangement of epoxides to carbonyl compounds. These systems include Brфnsted or Lewis acids [177-180], including $\mathrm{BF}_{3} . \mathrm{Et}_{2} \mathrm{O}$ [181-183], lithium salts [184], $\mathrm{MgBr}_{2}$ [185,186], $\mathrm{Pd}(\mathrm{OAc})_{2}$ in the presence of phosphine ligands [187], $\mathrm{InCl}_{3}$ [188] and $\mathrm{BiOClO}_{4} \cdot \mathrm{nH}_{2} \mathrm{O}$ [189]. Unfortunately, most such catalytic reagents create a number of environmental 
disadvantages, such as the production of large quantities of toxic or corrosive waste resulting from the use of stoichiometric quantities. Moreover, the rearrangement reactions mostly need to be carried out under anhydrous conditions at high temperatures for long reaction times.

Major effort has therefore been made to find environmentally friendly processes for the rearrangement of epoxides. The use of solid catalysis can overcome many of the limitations associated with the use of solution phase Lewis or Bronsted acid catalysts. In particular, various types of zeolites such as HY, HZSM-5 and offretite effect the rearrangement of styrene oxide, at $95{ }^{\circ} \mathrm{C}$ in toluene to give a good yield of phenylacetaldehyde [190-193]. Also, rearrangements of different epoxides over acidic zeolites at $200-300{ }^{\circ} \mathrm{C}$ have been reported [194].

Although such rearrangements are not simple electrophilic aromatic substitutions, as part of our ongoing interest in the use of zeolites and other solid catalysts and/or controlling agents for organic synthesis, we decided to investigate the scope and limitations of arylepoxide rearrangement reactions and to try to develop a simple process, involving mild conditions. Initially, we investigated the rearrangement of styrene oxide to phenylacetaldehyde (Scheme 19; $X=H$ ), over zeolite HZSM-5 $(\mathrm{Si} / \mathrm{Al}=40)$ in toluene as a solvent $[195,196]$. However, the yield of phenylacetaldehyde was never greater than $77 \%$, much less than the quantitative yield reported in the literature under the same reaction conditions [190]. Further investigation revealed that the remaining styrene oxide was converted into polymeric material that did not show up in the gas chromatographic analysis [195].<smiles>[X]c1ccc(C2CO2)cc1</smiles>

44

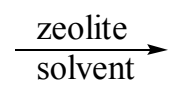

Scheme 19.<smiles>[X]c1ccc(CC=O)cc1</smiles>

45

In order to test the effect of the solvent in this process, several reactions of styrene oxide were carried out over zeolite HZSM-5, under identical conditions except for the nature of the solvent. The results obtained are recorded in Table 21. The results indicated that the yield obtained was very high when the reaction was carried out in chloroform or diethyl ether. However, the reaction was slow in methanol, presumably due to the weakening of the acidity of the catalytic sites by hydrogen bonding to methanol $[195,196]$. 
Table 21. Rearrangement of Styrene Oxide According to Scheme $19(\mathrm{X}=\mathrm{H})$ Over HZSM-5 in Various Solvents ${ }^{\mathrm{a}}$

\begin{tabular}{|l|l|l|l|}
\hline Solvent & t (h) & Conversion (\%) & Yield (\%) \\
\hline \hline Toluene & 5 & 100 & 59 \\
\hline $\mathrm{CH}_{2} \mathrm{Cl}_{2}$ & 4 & 66 & 58 \\
\hline $\mathrm{CHCl}_{3}$ & 4 & 100 & 94 \\
\hline $\mathrm{Et}_{2} \mathrm{O}$ & 5 & 100 & 95 \\
\hline $\mathrm{MeOH}$ & 5 & 30 & 26 \\
\hline $\mathrm{MeCOMe}$ & 6 & 100 & 63 \\
\hline
\end{tabular}

${ }^{\mathrm{a}}$ Styrene oxide $(8.3 \mathrm{mmol})$ and $\mathrm{HZSM}-5(\mathrm{Si} / \mathrm{Al}=40,0.5 \mathrm{~g})$ in solvent $(10 \mathrm{ml})$ at $20{ }^{\circ} \mathrm{C}$ under $\mathrm{N}_{2}$ for the indicated reaction time [196].

Further studies were conducted using various quantities of zeolite HZSM-5; different Si/Al ratios; and various reaction times. We found that the optimum condition for maximising the yield of phenylacetaldehyde $(\mathbf{4 5} ; \mathrm{X}=\mathrm{H})$ involved the use of HZSM-5 $(\mathrm{Si} / \mathrm{Al}=40,0.5 \mathrm{~g})$ and chloroform $(10$ $\mathrm{ml})$ for $8.3 \mathrm{mmol}$ of styrene oxide $(44 ; \mathrm{X}=\mathrm{H})$ at $20^{\circ} \mathrm{C}$ for $0.5-4 \mathrm{~h}[196]$.

A number of different acidic zeolites was then screened for efficacy in the rearrangement of styrene oxide (Scheme 19; $\mathrm{X}=\mathrm{H}$ ) under the optimised conditions. The results obtained are recorded in Table 22.

Table 22. Rearrangement of Styrene Oxide Over Various Zeolites According to Scheme 19 (X= H) ${ }^{\mathbf{a}}$

\begin{tabular}{|l|l|l|l|}
\hline Zeolite & t (h) & Conversion (\%) & Yield (\%) \\
\hline \hline HZSM-5 & 4 & 100 & 94 \\
\hline H-Mordenite & 6 & 61 & 39 \\
\hline HY & 6 & 77 & 56 \\
\hline HX & 6 & 20 & 14 \\
\hline HA & 6 & $<10$ & $<10$ \\
\hline H & 6 & 100 & 78 \\
\hline
\end{tabular}

${ }^{\mathrm{a}}$ Styrene oxide $(8.3 \mathrm{mmol})$ and zeolite $(0.5 \mathrm{~g})$ in $\mathrm{CHCl}_{3}(10 \mathrm{ml})$ at $20{ }^{\circ} \mathrm{C}$ under $\mathrm{N}_{2}$ for the indicated reaction time $[195,196]$.

The results indicated that all medium and large pore zeolites can accommodate the reaction and that quite strongly acidic sites are better for effective catalysis (HY is more effective than HX). HZSM-5 and H $\beta$ offered the highest yields $[195,196]$.

The reaction over a new sample of zeolite HZSM-5 in chloroform was applied to a range of substituted styrene oxides 44 (Scheme 19; Table 23). 
Table 23. Rearrangement of Substituted Styrene Oxide 44 According to Scheme 19 Over HZSM-5 ${ }^{\mathrm{a}}$

\begin{tabular}{|l|l|l|}
\hline $\mathbf{X}$ & Conversion (\%) & Yield (\%) of 45 \\
\hline \hline $\mathrm{H}$ & 100 & 77 \\
\hline $\mathrm{Me}$ & 100 & 73 \\
\hline $\mathrm{OMe}$ & 100 & $76^{\mathrm{b}}$ \\
\hline $\mathrm{Cl}$ & 100 & 92 \\
\hline $\mathrm{Br}$ & 100 & 75 \\
\hline $\mathrm{NO}_{2}$ & 100 & 92 \\
\hline
\end{tabular}

${ }^{\mathrm{a}} \mathrm{HZSM}-5$ (Si/Al: 40, $\left.0.5 \mathrm{~g}\right)$ and $33(8.3 \mathrm{mmol})$ in $\mathrm{CHCl}_{3}(10 \mathrm{ml})$ at $20{ }^{\circ} \mathrm{C}$ under $\mathrm{N}_{2}$ for $30 \mathrm{~min}[195,196]$.

${ }^{\mathrm{b}}$ After $1 \mathrm{~h}$.

The results indicated that the reaction was successful for a range of substituted styrene oxides 44 with electron-donating or electron-withdrawing groups [195,196]. Somewhat higher yields were obtained with electron-withdrawing groups. The reaction has been proven to be fast, efficient and general under mild conditions, which render it attractive for organic syntheses [195,196].

The procedure has also been applied to the rearrangement of 1,2-disubstituted epoxides such as those from cis- and trans-stilbenes, and of 1,1-disubstituted epoxides such as 1,1-diphenylethene oxide. Initially, we attempted the rearrangement of stilbene oxide (46) over HZSM-5 in chloroform. However, no reaction occurred, suggesting that stilbene oxide might not fit into the channels of zeolite HZSM-5. In view of the lack of success with the medium pore zeolite HZSM-5, the rearrangement of 46 was attempted over a large pore zeolite, H $\beta$. Indeed, the rearrangement of $\mathbf{4 6}$ over $\mathrm{H} \beta$ gave a mixture of the corresponding aldehyde 47 and ketone 48 (Scheme 20) in high overall yield after $4 \mathrm{~h}$ [196], with the ketone predominating. The yields of $\mathbf{4 7}$ and $\mathbf{4 8}$ were 16 and $72 \%$ respectively when the substrate was cis-stilbene oxide, but 22 and 69\% respectively for trans-stilbene oxide [196].<smiles>c1ccc(C2OC2c2ccccc2)cc1</smiles>

46

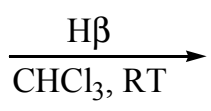<smiles>O=CC(c1ccccc1)c1ccccc1</smiles>

47<smiles>O=C(Cc1ccccc1)c1ccccc1</smiles>

48

Scheme 20.

However, the rearrangement of 2,2-diphenyloxirane (49) under similar conditions over $\mathrm{H} \beta$ gave only the corresponding aldehyde 47 in 82\% yield (Scheme 21) [196]. 


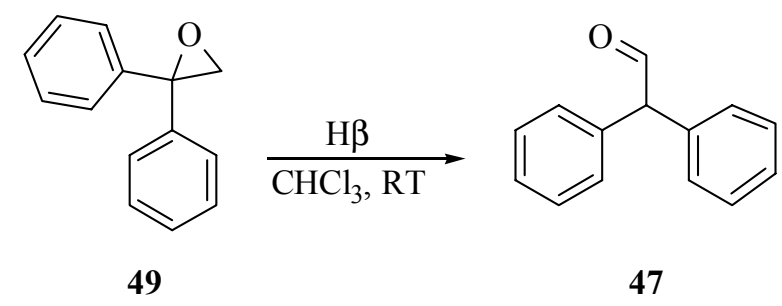

\section{Scheme 21.}

\section{CONCLUSION}

Zeolite catalysts offer possibilities for both catalysis and selectivity enhancement in electrophilic aromatic substitution reactions, where such effects are much needed to overcome various problems associated with the use of traditional methods. Zeolite catalysts offer approaches to parasubstituted aromatics as major products, with the advantage of easy separation of the catalyst from the reaction mixture. Zeolites can be recovered and reused to give almost the same yields and selectivities as those obtained when fresh zeolite is used, with the avoidance of toxic waste generated by traditional Lewis acids.

Various reaction types have been developed and several examples in which superior methodologies are particularly needed, namely nitration of simple benzenoids, 2,6-dialkylation of naphthalene, acylation, methanesulfonylation and halogenation of simple aromatic compounds, have been developed.

$\mathrm{HNO}_{3} / \mathrm{Ac}_{2} \mathrm{O} / \mathrm{H} \beta$ is an effective system for nitration of monosubstituted aromatic substrates. Alkylbenzenes and halogenobenzenes are nitrated in quantitative yields with excellent para selectivities using a stoichiometric quantity of nitric acid and enough acetic anhydride to convert all the nitric acid into acetyl nitrate and all the water into acetic acid. Dinitro compounds are not formed in any significant amounts.

However, when the nitration system is adapted to include TFAA, which enhances the reactivity considerably, the nitration of deactivated aromatics occurs readily. Optimisation of the process has enabled the most selective double nitration of toluene yet attained, giving 2,4-dinitrotoluene in high yield. It is recognised that trifluoroacetic anhydride's volatility, toxicity and cost may render it unattractive for larger scale commercial processes, but recovery of TFAA should be easy. 
In an alternative approach to mononitration of simple aromatics, dinitrogen tetroxide has been used over H $\beta$. This provides selectivity for para-substitution that is higher than in the traditional approach, though there is still need for further improvement of the system.

Highly regioselective dialkylation of naphthalene has been achieved over zeolite HM using tert-butyl alcohol as alkylating agent under autoclave conditions. The process provides a particularly convenient, high yielding and highly regioselective method for the synthesis of 2,6-di-tertbutylnaphthalene, which has been obtained in $60 \%$ yield with a 2,6/2,7 ratio of over 50 . Although this method is easily the most selective yet discovered for production of a 2,6-dialkylnaphthalene, it may be difficult to oxidise the tert-butyl groups to carboxyl groups. Therefore, there is still room for considerable improvement in the clean and selective synthesis of naphthalene-2,6-dicarboxylic acid.

Acetylation of aromatic ethers over zeolite $\mathrm{H} \beta$ or $\mathrm{HY}$ is a successful method that is highly selective for the position para to the alkoxy group. Deactivating groups cause considerable slowing of the reaction and in such cases it is better to use the more open and more active HY as catalyst.

The acylation of 2,3-dihydrobenzofuran (DHBF) with simple anhydrides over zeolite $\mathrm{H} \beta$ occurs readily over short reaction times under relatively mild conditions, giving the corresponding aromatic ketones regioselectively in good yields. In addition, yields of products obtained from reaction between DHBF and bulkier acylating agents such as trimethylacetic and benzoic anhydrides were improved upon by employing large pore zeolites for longer reaction times. The procedure was also applied to the synthesis of ethyl (2,3-dihydrobenzofuran-5-yl)glyoxylate. A high yield of the desired product could be obtained only by conducting the reaction in ethyl oxalyl chloride as solvent at a high temperature for a prolonged period in the presence of a large quantity of catalyst. Consequently, there is still room for improvement in the clean and selective synthesis of that compound.

Methanesulfonylation of toluene is less para-selective than arylsulfonylation, but quite high selectivity has been achieved in reactions that are relatively low yielding. The sodium-exchanged zeolite $\beta$ offers the possibility of very high para-selectivity. Alternatively, reasonable para-selectivity can be achieved in quite good yield by use of proton or some other exchanged forms of zeolite $\beta$. All of these cases provide much better para-selectivity than the published reaction with aluminium chloride and methanesulfonyl chloride and in most cases the yield is substantially improved too.

A system comprising $\mathrm{HNaX} / \mathrm{Bu}^{t} \mathrm{OCl} / \mathrm{MeCN}$ is effective for para-selective monochlorination of aromatic compounds. The procedure has been applied successfully to a wide range of aromatic 
substrates under mild conditions to give excellent yields of monochlorinated aromatics with good to excellent regioselectivity.

High para-selectivity has been achieved in bromination of toluene by use of tert-butyl hypobromite as reagent, $\mathrm{HNaX}$ zeolite as catalyst, and a solvent mixture comprising diethyl ether and tetrachloromethane. Also, the reaction of bromine with substituted benzenes of moderate activity in the presence of sufficient $\mathrm{NaY}$ zeolite at room temperature provides a convenient, high yielding and highly regioselective method for synthesis of para-brominated products. Consequently, this approach becomes a commercially realistic possibility for the synthesis of para-bromo substituted benzenes.

We continue to explore the possibilities for exploitation of zeolites in selective aromatic susbstitution reactions.

\section{ACKNOWLEDGEMENTS}

G. A. El-Hiti thanks the University of Wales Swansea for financial support and the Royal Society of Chemistry for an international author grant.

\section{REFERENCES}

[1] RSC Clean Technology Monographs, Clark, J.H. Ed.; Cambridge, 2000.

[2] Clark, J.H. Green Chem. 1999, 1, 1.

[3] Green Chemistry: Challenging Perspectives; Tundo, P.; Anastas, P.T., Ed.; Oxford Science: Oxford, 2000.

[4] Anastas, P.T.; Warner, J.C. Green Chemistry: Theory and Practice; Oxford University Press: Oxford, 1998.

[5] Spagnol, M.; Gilbert, L.; Allby, D. In The Roots of Organic Development; Desmurs, J.-R.; Rattoy, S., Ed.; Elsevier: Amsterdam, 1996, pp. 29.

[6] Chemistry of Waste Minimisation; Clark, J.H., Ed.; Chapman and Hall: London, 1995.

[7] Suzuki, K.; Kitagawa, H.; Mukaiyama, T. Bull. Chem. Soc. Jpn., 1993, 66, 3729.

[8] Mukaiyama, T.; Ohno, T.; Nishimura, T.; Suda, S.; Kobayashi, S. Chem. Lett., 1991, 1059.

[9] Roberts, R.M.; Khalaf, A.A. Friedel-Crafts Alkylation; Marcel Dekker: New York, 1984.

[10] Olah, G.A. Friedel-Crafts Chemistry; Wiley-Interscience: New York, 1973.

[11] Sharman, S.H. J. Am. Chem. Soc., 1962, 84, 2945. 
[12] Smith, K.; El-Hiti, G.A. Curr. Org. Synth., 2004, 1, 253.

[13] Clark, J.H. Acc. Chem. Res., 2002, 35, 791.

[14] Principles and Practice of Heterogeneous Catalysis; Thomas, J.M.; Thomas, W.J., Ed.; VCH: Weinheim, 1997.

[15] Catalysis of Organic Reactions using Supported Inorganic Reagents; Clark, J.H., Ed.; VCH: New York, 1994.

[16] Clark, J.H.; Cullen, S.R.; Barlow, S.J.; Bastock, T.W. J. Chem. Soc., Perkin Trans. 2, 1994, 1117.

[17] Delaude, L.; Laszlo, P.; Smith, K. Acc. Chem. Res., 1993, $26,607$.

[18] Smith, K. In New Aspects of Organic Synthesis II; Yoshida, Z.; Ohshiro, Y., Ed.; Kadonsha: Tokyo and VCH Weinheim, 1992, pp. 43.

[19] Batters, M. In Solid Supports and Catalysts in Organic Synthesis; Smith, K., Ed.; Ellis Horwood: Chichester, 1992, pp. 130-170.

[20] Smith, K. In Catalysis of Organic Reactions; Scaros, M.G.; Prunier, M.L., Ed.; Marcel Dekker: New York, 1991, pp. 91.

[21] Heaney, H. The Bimolecular Aromatic Friedel-Crafts Reactions In Comprehensive Organic Synthesis; Trost, B.M. Ed.; Pergamon Press: Oxford, 1991, Vol. 2, Chapter 3.2, pp. 733-752.

[22] Introduction to Zeolite Science and Practice; van Bekkum, H.; Flanigan, E.M.; Jansen, J.C., Ed.; Stud. Surf. Sci. Catal., 1991, vol. 58.

[23] Electrophilic Aromatic Substitution; Taylor, R., Ed.; John Wiley and Sons: Chichester, 1990.

[24] Hölderich, W.; Hesse, M.; Näumann, F. Angew. Chem., Int. Ed. Engl., 1988, 27, 226.

[25] Schofield, K. Aromatic Nitration; Cambridge University Press: Camridge, 1980.

[26] Olah, G.A.; Malhotra, R.; Narang, S.C. Nitration: Methods and Mechanisms; VCH: New York, 1989.

[27] Olah, G.A.; Kuhn, S.J.; Flood, S.H.; Evans, J.C. J. Am. Chem. Soc., 1962, 84, 3687.

[28] Coombes, R.G.; Moodie, R.B.; Schofield, K. J. Chem. Soc. B, 1968, 800.

[29] Coombes, R.G.; Crout, D.H.G.; Hoggett, J.G.; Moodie, R.B.; Schofield, K. J. Chem. Soc. B, 1970, 347.

[30] Kurz, M.E.; Yang, L.T.A.; Zahora, E.P.; Adams, R.C. J. Org. Chem., 1973, 38, 2271.

[31] Smith, K. Bull Soc. Chim. Fr., 1989, 272. 
[32] Nagy, S.M.; Zubkov, E.A.; Shubin, V.G. Bull. Acad. Sci. USSR, Chem. Ser., 1989, 1780 (pp. 1933 in the Russian original).

[33] Nagy, S.M.; Yarovoy, K.A.; Shakirov, M.M.; Shubin, V.G.; Vostrikova, L.A.; Ione, K.G. J. Mol. Catal., 1991, 64, L31.

[34] Nagy, S.M.; Yarovoy, K.A.; Shubin, V.G.; Vostrikova, L.A. J. Phys. Org. Chem., 1994, 7, 385.

[35] Kwok, T.J.; Jayasuriya, K.; Damavarapu, R.; Brodman, B.W. J. Org. Chem., 1994, 59, 4939.

[36] Choudary, B.M.; Sateesh, M.; Lakshmi Kantam, M.; Koteswara Rao, K.; Ram Prasad, K.V.; Raghavan, K.V.; Sarma, J.A.R.P. Chem. Commun., 2000, 25.

[37] Gal, A.; Kurahashi, M.; Kuzumoto, M. J. Phys. Chem. A., 2000, 104, 10821.

[38] Kogelbauer, A.; Vassena, D.; Prins, R.; Armor, J.N. Catal. Today, 2000, 55, 151.

[39] Vassena, D.; Kogelbauer, A.; Prins, R. Catal. Today, 2000, 60, 275.

[40] Peng, X.; Fukui, N.; Mizuta, M.; Suzuki, H. Org. Biomol. Chem., 2003, 1, 2326.

[41] Patil, P.T.; Malshe, K.M.; Dagade, S.P.; Dongare, M.K. Catal. Commun., 2003, 4, 429.

[42] Smith, K.; Musson, A.; DeBoos, G.A. J. Org. Chem., 1998, 63, 8448.

[43] Haouas, M.; Kogelbauer, A.; Prins, R. Catal. Lett., 2000, 70, 61.

[44] Haouas, M.; Bernascani, S.; Kogelbauer, A.; Prins, R. Phys. Chem. Chem. Phys., 2001, 3, 5067.

[45] Claridge, R.P.; Llewellyn Lancater, N.; Miller, R.W.; Moodie, R.B.; Sandall, J.P.B. J. Chem. Soc., Perkin Trans. 2, 1999, 1815.

[46] Schumacher, I. Eur. Patent, 0,053,031, 1981.

[47] Germain, A.; Akouz, T.; Figueras, F. J. Catal., 1994, 147, 163.

[48] Germain, A.; Akouz, T.; Figueras, F. Appl. Catal. A: Gen., 1996, 136, 57.

[49] Peng, X.; Suzuki, H. Org. Lett., 2001, 3, 3431.

[50] Salakhutdinov, N.F.; Ione, K.G.; Kobzar, E.A.; Malysheva, L.V. Zh. Org. Khim., 1993, 29, 546.

[51] Suzuki, H.; Yonezawa, S.; Nonoyama, N.; Mori, T. J. Chem. Soc., Perkin Trans. 1, 1996, 2385.

[52] Bak, R.R.; Smallridge, A.J. Tetrahedron Lett., 2001, 42, 6767.

[53] Smith, K.; Almeer, S.; Black, S.J. Chem. Commun., 2000, 1571. 
[54] Smith, K.; Almeer, S.; Black, S.J.; Peters, C. J. Mater. Chem., 2002, 12, 3285.

[55] Peng, X.; Suzuki, H.; Lu, C. Tetrahedron Lett., 2001, 42, 4357.

[56] Smith, K.; Almeer, S.; Peters, C. Chem. Commun., 2001, 2748.

[57] Vassena, D.; Kogelbauer, A.; Prins, R. Stud. Surf. Sci. Catal., 1999, 125, 501.

[58] Smith, K.; Gibbins, T.; Millar, R.W.; Claridge, R.P. J. Chem. Soc. Perkin Trans. 1, 2000, 2753.

[59] Waller, F.J.; Barrett, A.G.M.; Braddock, D.C.; Ramprasad, D. Tetrahedron Lett., 1998, 39, 1641.

[60] Gigante, B.; Prazeres, A.O.; Marcelo-Cuto, M.J.; Cornélis, A.; Laszlo, P. J. Org. Chem., 1995, 60,3445 .

[61] Bourne, E.J.; Stacey, M.; Tatlow, J.C.; Tedder, J.M. J. Chem. Soc., 1952, 1695.

[62] Loktev, A.S.; Chekriy, P.S.; Stud. Surf. Sci. Catal., 1994, 84, 1845.

[63] Pu, S.-B.; Inui, T. Appl. Catal. A: Gen., 1996, 146, 305.

[64] Pu, S.-B.; Inui, T. Zeolites, 1996, 17, 334.

[65] Kitabayashi, S.; Shindo, T.; Ono, K.; Ohnuma, H. Nippon Kagaku Kaishi, 1996, 624 (Chem. Abstr., 1996, 125, 89575m).

[66] Armengol, E.; Corma, A.; García, H.; Primo, J. Appl. Catal. A: Gen., 1997, 149, 411.

[67] Anunziata, O.A.; Pierella, L.B. Catal. Lett., 1997, 44, 259.

[68] Gläser, R.; Li, R.; Hunger, M.; Ernst, S.; Weitkamp, J. Catal. Lett., 1998, 50, 141.

[69] Motoyuki, M.; Yamamoto, K.; McWilliams, J.P.; Bundens, R.G. U. S. Patent 5,744,670, 1998.

[70] Marathe, R.P.; Mayadevi, S.; Pardhy, S.A.; Sabne, S.M.; Sivasanker, S. J. Mol. Catal. A: Chem., 2002, 181, 201.

[71] He, C.; Liu, Z.; Fajula, F.; Moreau, P. Chem. Commun., 1998, 1999.

[72] Colón, G.; Ferino, I.; Rombi, E.; Selli, E.; Forni, L.; Magnoux, P.; Guisnet, M. Appl. Catal. A: Gen., 1998, 168, 81.

[73] Ferino, I.; Monaci, R.; Rombi, E.; Solinas, V.; Magnoux, P.; Guisnet, M. Appl. Catal. A: Gen., 1999, 183, 303.

[74] Pazzuconi, G.; Perego, C.; Millini, R.; Frigerio, F.; Mansani, R.; Rancati, D. U. S. Patent, 6,147,270, 2000.

[75] Moreau, P.; He, C.; Liu, Z.; Fajula, F. J. Mol. Catal. A: Chem., 2001, 168, 105. 
[76] Millini, R.; Frigerio, F.; Bellussi, G.; Pazzuconi, G.; Perego, C.; Pallesel, P.; Romano, U. J. Catal., 2003, 217, 298.

[77] Olah, G.A.; Olah, J.A. J. Am. Chem. Soc., 1976, 98, 1839.

[78] Fraenkel, D.; Cherniavsky, M.; Ittah, B.; Levy, M. J. Catal., 1986, 101, 273.

[79] Cutrufello, M.G.; Ferino, I.; Monaci, R.; Rombi, E.; Solinas, V.; Magnoux, P.; Guisnet, M. Appl. Catal. A: Gen., 2003, 241, 91.

[80] Brzozowski, R.; Tęcza, W. Appl. Catal. A: Gen., 1998, 166, 21.

[81] Katayama, A.; Toba, M.; Takeuchi, G.; Mizukami, F.; Niwa, S.-I.; Mitamura, S. J. Chem. Soc. Chem. Commun., 1991, 39.

[82] Schmitz, A.D.; Song, C.S. Catal. Today, 1996, 31, 195.

[83] Kim, J.-H.; Sugi, Y.; Matsuzaki, T.; Hanaoka, T. Kubota, Y.; Tu, X.; Matsumoto, M.; Nakata, S.; Kato, A.; Seo, G.; Pak, C. Appl. Catal. A: Gen., 1995, 131, 15.

[84] Schmitz, A.D.; Song, C.S. Catal. Lett., 1996, 40, 59.

[85] Moreau, P.; Finiels, A.; Geneste, P.; Solofo, J. J. Catal., 1992, 136, 487.

[86] Notte, P.P.B.; Poncelet, G.M.J.L.; Remy, M.J.H.; Lardinois, P.E.M.G.; van Hoecke, M.J.M. Eur. Patent 0,528,096, 1993.

[87] Moreau, P.; Finiels, A.; Geneste, P.; Moreau, F.; Solofo, J. J. Org. Chem. 1992, 57, 5040.

[88] Liu, Z.; Moreau, P.; Fajula, F. Chem. Coumm., 1996, 2653.

[89] Liu, Z.; Moreau, P.; Fajula, F. Appl. Catal. A: Gen,. 1997, 159, 305.

[90] Smith, K.; Robers, S.D.; El-Hiti, G.A. Org. Biomol. Chem., 2003, 1, 1552.

[91] Chiche, B.; Finiels, A.; Gauthier, C.; Geneste, P.; Graille, J.; Pioch, D. J. Org. Chem., 1986, $51,2128$.

[92] Chiche, B.; Finiels, A.; Gauthier, C.; Geneste, P.; Graille, J.; Pioch, D. J. Mol. Catal., 1987, $42,229$.

[93] Gauthier, C.; Chiche, B.; Finiels, A.; Geneste, P. J. Mol. Catal., 1989, 50, 219.

[94] Corma, A.; Climent, M.J.; Garcia, H.; Primo, J. Appl. Catal., 1989, 49, 109.

[95] Akporiaye, D.E.; Daasvatn, K.; Solberg, J.; Stöcker, M. Stud. Surf. Sci. Catal., 1993, 78, 521.

[96] Wang, Q.L.; Ma, Y.D.; Ji, X.D.; Yan, H.; Qui, Q. J. Chem. Soc., Chem. Commun., 1995, 2307.

[97] Singh, A.P.; Bhattacharya, D.; Sharma, S. J. Mol. Catal. A: Chem., 1995, 102, 139. 
[98] Gaare, K.; Akporiaye, D. J. Mol. Catal. A: Chem., 1996, 109, 177.

[99] Ranu, B.C.; Ghosh, K.; Jana, U. J. Org. Chem., 1996, 61, 9546.

[100] Sreekumar, R.; Padmakumar, R. Synth. Commun., 1997, 27, 777.

[101] De Castro, C.; Primo, J.; Corma, A. J. Mol. Catal. A: Chem., 1998, 134, 215.

[102] Derouane, E.G.; Dillon, C.J.; Bethell, D.; Derouane-Abd Hamid, S.B. J. Catal. 1999, 187, 209.

[103] Freese, U.; Heinrich, F.; Roessner, F. Catal. Today, 1999, 49, 237.

[104] Heinichen, H.K.; Hölderich, W.F. J. Catal., 1999, 185, 408.

[105] Moreau, P.; Finiels, A.; Meric, P. J. Mol. Catal. A: Chem., 2000, 154, 185.

[106] Escola, J.M.; Davis, M.E. Appl. Catal. A: Gen., 2001, 214, 111.

[107] Beers, A.E.W.; Nijhuis, T.A.; Kapteijn, F.; Moulijn, J.A. Micropor. Mesopor. Mater., 2001, 48,279 .

[108] Bigi, F.; Carloni, S.; Flego, C.; Maggi, R.; Mazzacani, A.; Rastelli, M.; Sartori, G. J. Mol. Catal. A: Chem., 2002, 178, 139.

[109] Botella, P.; Corma, A.; Navarro, M.T.; Rey, F.; Sastre, G. J. Catal., 2003, $217,406$.

[110] Klisáková, J.; Červený, L.; Čejka, J. Appl. Catal. A: Gen., 2004, 272, 79.

[111] Kurek, P.R.; U. S. Patent 5,126,489, 1992.

[112] Spagnol, M.; Gilbert, L.; Benazzi, E.; Marcilly, C. U. S. Patent 5,817,878, 1998.

[113] Davis, M.E. Micropor. Mesopor. Mater., 1998, 21, 173.

[114] Bezouhanova, C.P. Appl. Catal. A: Gen., 2002, 229, 127.

[115] Smith, K.; Zhenhua, Z.; Hodgson, P.K.G. J. Mol. Catal. A: Chem,. 1998, 134, 121.

[116] Smith, K.; El-Hiti, G.A.; Jayne, A.J.; Butters, M. Org. Biomol. Chem., 2003, 1, 2321.

[117] Smith, K.; El-Hiti, G.A.; Jayne, A.J.; Butters, M. Org. Biomol. Chem., 2003, 1, 1560.

[118] Taylor, R. In Comprehensive Chemical Kinetics; Banford, C.H.; Tipper, C.F.H., Ed.; Elsevier: New York, 1972, pp. 77-83.

[119] Jensen, F.R.; Goldman, G. In Friedel-Crafts and Related Reactions; Olah, G.A., Ed.; WileyInterscience: New York, 1964, vol. III, pp. 1319-1367.

[120] Jensen, F.R.; Brown, H.C. J. Am. Chem. Soc., 1958, 80, 4046.

[121] Olah, G. A.; Kobayashi, S.; Nishimura, J. J. Am. Chem. Soc., 1973, 95, 564. 
[122] Daley, S.; Trevor, K.A.; Randles, K.R.; Gott, B.D. PCT Int. Appl. WO93 18,000, 1993 (Chem. Abstr., 1994, 120, 54320u).

[123] Sipe Jr, H.J.; Clary, D.W.; White, S.B. Samuel, B. Synthesis, 1984, 283.

[124] Ueda, M.; Uchiyama, K.; Kano, T. Synthesis, 1984, 323.

[125] Laidlaw, P.; Bethell, D.; Brown, S.M.; Watson, G.; Willock, D. J.; Huchings, G.J. J. Mol. Catal. A, 2002, 178, 205.

[126] Choudary, B.M.; Chowdari, N.S.; Kantam, M.L.; Kannan, R. Tetrahedron Lett., 1999, 40, 2859.

[127] Choudary, B.M.; Chowdari, N.S.; Kantam, M.L. J. Chem. Soc., Perkin Trans. 1, 2000, 2689.

[128] Répichet, S.; Le Roux, C.; Hernandez, P.; Dubac, J.; Desmurs, J.-R. J. Org. Chem., 1999, 64, 6479.

[129] Répichet, S.; Le Roux, C.; Dubac, J.Tetrahedron Lett., 1999, 40, 9233.

[130] Marquié, J.; Laporterie, A.; Dubac, J.; Roques, N.; Desmurs, J.-R. J. Org. Chem., 2001, 66, 421.

[131] Desmurs, J.-R.; Dubac, J.; Laporterie, A.; Laporte, C.; Marquié, J. PCT Int. Appl. WO98 40,339, 1998 (Chem. Abstr., 1998, 129, 244928g).

[132] Laporte, C.; Marquié, J.; Laporterie, A.; Desmurs, J.-R.; Dubac, J. C. R. Acad. Sci. IIC, 1999, 2,455 .

[133] Smith, K.; Ewart, G.M.; Randles, K.R. J. Chem. Soc. Perkin Trans. 1, 1997, 1085.

[134] Smith, K.; Ewart, G.M.; El-Hiti, G.A.; Randles, K.R. Org. Biomol. Chem., 2004, 2, 3150.

[135] Ratnasamy, P.; Singh, A.P.; Sharma, S. Appl. Catal. A: Gen., 1996, 135, 25.

[136] de la Mare, P.B.D. Electrophilic halogenation; Cambridge University Press: Cambridge, 1976.

[137] Lindsay-Smith, J.R.; McKeer, L.C. Tetrahedron Lett., 1983, 24, 3117.

[138] Olah, G.A.; Ohannesian, L.; Arvanaghi, M. Synthesis, 1986, 868.

[139] Smith, K.; Butters, M.; Nay, B. Tetrahedron Lett., 1988, 29, 1319.

[140] Lindsay-Smith, J.R.; McKeer, L.C.; Taylor, J.M. J. Chem. Soc., Perkin Trans. 2, 1989, 1529 and 1537.

[141] Larock, R.C. Comprehensive Organic Transformations; VCH: New York, 1989, pp. 316.

[142] Delaude, L.; Laszlo, P. J. Org. Chem., 1990, 55, 5260. 
[143] Delaude, L.; Laszlo, P. Catal. Lett., 1990, 5, 35.

[144] March, J. Advanced Organic Chemistry; Wiley: New York, 1992, pp. 531.

[145] Antenucci, D.; Delaude, L.; Fransolet, A.-M.; Laszlo, P. J. Catal., 1992, 135, 92.

[146] Goldberg, Y.; Alper, H. J. Org. Chem., 1993, 58, 3072.

[147] Singh, A.P.; Kumar, S.B.; Paul, A.; Raj, A. J. Catal., 1994, 147, 360.

[148] Singh, A.P.; Kumar, S.B. Appl. Catal. A: Gen., 1995, 126, 27.

[149] Singh, A.P.; Sharma, S.; Kale, S.M. J. Mol. Catal. A: Chem., 1997, 127, 101.

[150] Satterley, B. W.; Hausladen, M.C.; Lund, C.R.F. Zeolites, 1997, 19, 434.

[151] Deb, S.; Das, K.R. J. Sci. Ind. Res., 1998, 57, 539.

[152] Kale, S.M.; Singh, A.P. J. Mol. Catal. A: Chem., 1999, 138, 263.

[153] Singh, A.P.; Kale, S.M. Catal. Today, 1999, 49, 245.

[154] Hausladen, M.C.; Lund, C.R.F. Appl. Catal. A: Gen., 2000, 190, 269.

[155] Hausladen, M.C.; Cyganovich, R.C.; Huang, H.Y.; Lund, C.R.F. Appl. Catal. A: Gen., 2001, 219, 1 and references cited therein.

[156] Chang, C.-C.; Burger, M.J.; Faitar, G.M.; Lund, C.R.F. J. Catal., 2001, 202, 59.

[157] Kale, S.M.; Singh, A.P. Appl. Catal. A: Gen., 2002, 228, 1.

[158] Kale, S.M.; Singh, A.P. J. Mol. Catal. A: Chem., 2002, 184, 399.

[159] Smith, K.; Butters, M.; Paget, W.E.; Goubet, D.; Formentin, E.; Nay, B. Green Chem., 1999, 1,83 .

[160] Wortel, Th.M.; Oudijn, D.; Vleugel, C.J.; Roelofsen, D.P.; van Bekkum, H. J. Catal. 1979, 60, 110.

[161] van Dijk, J.; van Daalen, J.J.; Paerels, G.B. Recl. Trav. Chim. Pays-Bas, 1974, 93, 72.

[162] Miyake, T.; Sekizawa, K.; Hironaka, T.; Tsutsumi, Y. U. S. Patent 4,861,929, 1989.

[163] Suzuki, T.; Higuchi, Y. U. S. Patent 4,822,933, 1989.

[164] Singh, A.P.; Mirajkar, S.P.; Sharma, S. J. Mol. Catal. A.: Chem., 1999, 150, 241.

[165] Narender, N.; Krishna Mohan, K.V.V.; Vinod Reddy, R..; Srinivasu, P.; Kulkarni, S.J.; Reghavan, K.V. J. Mol. Catal. A.: Chem., 2003, 192, 73.

[166] Smith, K.; He, P.; Taylor, A. Green Chem., 1999, 1, 35.

[167] Smith, K.; El-Hiti, G.A.; Hammond, M.E.W.; Bahzad, D.; Li, Z.; Siquet, C. J. Chem. Soc., Perkin Trans. 1, 2000, 2745. 
[168] Smith, K.; Bahzad, D. C. Chem. Commun., 1996, 467.

[169] de la Vega, F.; Sasson, Y. Zeolites, 1989, 9, 418.

[170] de la Vega, F.; Sasson, Y. J. Chem. Soc., Chem. Commun., 1989, 653.

[171] de la Vega, F.; Sasson, Y.; Huddersman, K. Zeolites, 1991, 11, 617.

[172] de la Vega, F.; Sasson, Y.; Huddersman, K. Zeolites, 1993, 13, 341.

[173] Parker, R.E.; Isaacs, N.S. Chem. Rev., 1959, 59, 737.

[174] Rao, A.S.; Paknikar, S.K.; Kirtane, J.G. Tetrahedron, 1983, 39, 2323.

[175] Gorzynski Smith, J. Synthesis, 1984, 629.

[176] March, J. Advanced Organic Chemistry; John Wiley and Sons: New York, 1992, chap. 18.

[177] Rickborn, B. In Comrehensive Organic Synthesis; Trost, B.M.; Fleming, I., Ed.; Pergamon Press: New York, 1991, vol. 3, chap. 3.3, pp. 733.

[178] Rickborn, B.; Gerkin, R.M. J. Am. Chem. Soc., 1968, 90, 4193.

[179] Stork, G.; Schulenberg, J.W. J. Am. Chem. Soc., 1962, 84, 284.

[180] Eliel, E.L.; Delmonte, D.W. J. Am. Chem. Soc., 1958, 80, 1744.

[181] House, H.O. J. Am. Chem. Soc., 1955, 77, 3070.

[182] House, H.O. J. Am. Chem. Soc., 1955, 77, 5083.

[183] Vankar, Y.D.; Saksena, R.K.; Bawa, A. Chem. Lett., 1989, 1241.

[184] Rickborn, B.; Gerkin, R.M. J. Am. Chem. Soc., 1971, 93, 1693.

[185] Naqvi, S.M.; Horwitz, J.P.; Filler, R. J. Am. Chem. Soc., 1957, 79, 6283.

[186] House, H.O. Org. Synth. Coll. Vol. IV, 1973, 375.

[187] Kulasegaram, S.; Kulawiec, R.J. J. Org. Chem., 1997, 62, 6547.

[188] Ranu, B.C.; Jana, U. J. Org. Chem., 1998, 63, 8212.

[189] Anderson, A.M.; Blazek, J.M.; Garg, P.; Payne, B.J.; Mohan, R.S. Tetrahedron Lett., 2000, $41,1527$.

[190] Ruiz-Hitzky, E.; Casal, B. J. Catal., 1985, 92, 291.

[191] Paparatto, G.; Gregorio, G. Tetrahedron Lett., 1988, 29, 1471.

[192] Brunel, D.; Chamoumi, M.; Chiche, B.; Finiels, A.; Gauthier, G.; Geneste, P.; Graffin, P.; Marichez, F.; Moreau, P. Stud. Surf. Sci. Catal., 1989, 52, 139.

[193] Chamoumi, M.; Brunel, D.; Geneste, P.; Moreau, P.; Solofo, J. Stud. Surf. Sci. Catal., 1991, $59,573$. 
[194] Matsumoto, S.; Nitta, M.; Aomura, K. Bull. Chem. Soc. Jpn., 1974, 47, 1537.

[195] Smith, K.; Al-Shamali, M. Proceedings of $12^{\text {th }}$ International Zeolite Conference, Mater. Res. Soc., Warrendale, 1999, Vol. II, 1129.

[196] Smith, K.; El-Hiti, G.A.; Al-Shamali, M. Prepared manuscript. 